Georgia State University

ScholarWorks @ Georgia State University

Counseling and Psychological Services

Dissertations

Department of Counseling and Psychological

Services

Spring 5-12-2017

\title{
Enhancing The Seeking Safety Group Intervention With Trauma Sensitive Yoga Practice: A Program Evaluation
}

Thomas M. Murphy

Follow this and additional works at: https://scholarworks.gsu.edu/cps_diss

\section{Recommended Citation}

Murphy, Thomas M., "Enhancing The Seeking Safety Group Intervention With Trauma Sensitive Yoga

Practice: A Program Evaluation." Dissertation, Georgia State University, 2017.

doi: https://doi.org/10.57709/10115776

This Dissertation is brought to you for free and open access by the Department of Counseling and Psychological Services at ScholarWorks @ Georgia State University. It has been accepted for inclusion in Counseling and Psychological Services Dissertations by an authorized administrator of ScholarWorks @ Georgia State University. For more information, please contact scholarworks@gsu.edu. 


\section{ACCEPTANCE}

This dissertation, ENHANCING THE SEEKING SAFETY GROUP INTERVENTION WITH TRAUMA SENSITIVE YOGA PRACTICE: A PROGRAM EVALUATION, by THOMAS M. MURPHY, was prepared under the direction of the candidate's Dissertation Advisory Committee. It is accepted by the committee members in partial fulfillment of the requirements for the degree, Doctor of Philosophy, in the College of Education and Human Development, Georgia State University.

The Dissertation Advisory Committee and the student's Department Chairperson, as representatives of the faculty, certify that this dissertation has met all standards of excellence and scholarship as determined by the faculty.

Catherine Y. Chang, Ph.D.

Committee Co-Chair

Jane Brack, Ph.D.

Committee Member
Franco Dispenza, Ph.D.

Committee Co-Chair

Date

Brian Dew, Ph.D.

Chairperson, Department of Counseling

\& Psychological Services

Paul Alberto, Ph.D.

Dean, College of Education and

Human Development

Laura Shannonhouse, Ph.D.

Committee Member 


\begin{abstract}
AUTHOR'S STATEMENT
By presenting this dissertation as a partial fulfillment of the requirements for the advanced degree from Georgia State University, I agree that the library of Georgia State University shall make it available for inspection and circulation in accordance with its regulations governing materials of this type. I agree that permission to quote, to copy from, or to publish this dissertation may be granted by the professor under whose direction it was written, by the College of Education's Director of Graduate Studies, or by me. Such quoting, copying, or publishing must be solely for scholarly purposes and will not involve potential financial gain. It is understood that any copying from or publication of this dissertation which involves potential financial gain will not be allowed without my written permission.
\end{abstract}

Thomas Murphy 


\title{
NOTICE TO BORROWERS
}

All dissertations deposited in the Georgia State University library must be used in accordance with the stipulations prescribed by the author in the preceding statement. The author of this dissertation is:

\author{
Thomas Matthew Murphy \\ 163 Feld Avenue \\ Decatur, GA 30030
}

The directors of this dissertation are:

Catherine Y. Chang and Franco Dispenza

Department of Counseling \& Psychological Services

College of Education and Human Development

Georgia State University

Atlanta, GA 30303 


\title{
CURRICULUM VITAE
}

\author{
Thomas M. Murphy
}

ADDRESS:

163 Feld Avenue

Decatur, GA 30030

\section{EDUCATION:}

$\begin{array}{lll}\text { Ph.D. } & 2017 & \begin{array}{l}\text { Georgia State University } \\ \text { College of Education \& } \\ \text { Human Development } \\ \text { Counselor Education \& Practice }\end{array} \\ & 2012 & \begin{array}{l}\text { Georgia State University } \\ \text { College of Education \& } \\ \text { Master of Science }\end{array} \\ & \begin{array}{l}\text { Human Development } \\ \text { Clinical Mental Health Counseling }\end{array} \\ & \\ \text { Bachelor of Arts } & 1985 & \text { Washington \& Lee University } \\ & \text { Psychology }\end{array}$

\section{PROFESSIONAL EXPERIENCE:}

May, 2013 - present Doctoral Student/Graduate Research Assistant. Georgia State University

- Department of Counseling and Psychological Services.

Admissions Officer, CPS Department

Academic Program Review, CPS Department

Instructor of Record (Skills), CPS Department

Teaching Assistant, CPS Department

Instructor of Undergraduate Online Courses, CPS Department

May, 2015 - present Clinical Practitioner/Volunteer Counselor, Positive Impact Health Centers

- Midtown

Jul, 2014 - Apr, 2016 Doctoral Practicum/Intern, Positive Impact Health Centers - Midtown

Aug, 2013 - May, 2014 Supervisor in Training. Georgia State University.

2012 - May 2013 Clinical Intern. Odyssey Family Counseling, College Park, GA. 


\section{PRESENTATIONS AND PUBLICATIONS:}

Dispenza, F., Murphy, T., \& Zeligman, M. (Under Review).Career development of sexual minority men living with HIV: A grounded theory study.

Zeligman, M., Dispenza, F., Chang, C., Levy, D., McDonald, C., \& Murphy, T. (Under Review). Motivational interviewing training and evaluation in mental health counseling programs.

McCullough, J., Dispenza, F., Parker, L., Viehl, C., Chang, C., \& Murphy, T. (In Press). The counseling experiences of transgender and gender nonconforming clients. Journal of Counseling and Development.

Murphy, T. (2015). Reflections on treating trauma effectively with LGBTQ clients. Association For Lesbian, Gay, Bisexual \& Transgender Issues in Counseling Newsletter

Grad, R., Elston, N., McDonald, C.P., Murphy, T., Tolleson, A., Golubovic, N. \& Huffstead, M. (2016). Self-care and professional identity: Cornerstone to wellness and promoted within our CSI chapter. American Counseling Association, Montreal, Canada.

Murphy, T. \& Golubovic, N. (2015). Looking for the line: Ethics and culturally competent supervision in counselor education doctoral student preparation. Association of Counselor Educators and Supervisors, Philadelphia, PA.

Huffstead, M. \& Murphy, T. (2015). Counselor preparedness and competence working with biracial/multiracial individuals. Association of Counselor Educators and Supervisors, Philadelphia, PA.

McCullough, J., Murphy, T. (2015, January) Transgender advocacy and mental health. Positive Impact, Atlanta, GA.

Murphy, T., Elston, N. (2014, October). The influence of private social online social networks on mental health counseling cohorts. Southern Association of Counselor Educators and Supervisors, Birmingham, AL.

Dispenza, F, Elston, N, McCullough, J, Murphy, T, Viehl, C. (2014, October). Sexual Orientation and Gender Diversity Competencies of Counselor Educators. Southern Association of Counselor Educators and Supervisors, Birmingham, AL.

\section{PROFESSIONAL SOCIETIES AND ORGANIZATIONS}

2010

2011
American Counseling Association

Chi Sigma Iota Honor Society 
Enhancing the Seeking Safety Group Intervention with Trauma Sensitive Yoga Practice: A Program Evaluation

by

Thomas Murphy

Under the Direction of Drs. Catherine Y. Chang \& Franco Dispenza

\begin{abstract}
Seeking Safety is an evidence-based manualized group counseling intervention designed to address the intersection of trauma and addiction. Trauma-sensitive yoga practice has been shown to be effective as an adjunct treatment in addictions. This qualitative utilization-focused program evaluation analyzed the effectiveness of enhancing Seeking Safety with a traumasensitive yoga practice integrated into the Seeking Safety group intervention. The author utilized archival interviews, focus groups and documents collected from a community mental health agency. Data included client interviews, key informant interviews, and demographics. Data were analyzed using narrative analysis of transcripts and documents to assess the efficacy of Seeking Safety with the yoga enhanced intervention. Implications and recommendations for further research on the use of trauma-sensitive yoga with Seeking Safety are discussed.

INDEX WORDS: Trauma, Yoga, Program evaluation, Utilization-focused, Addiction
\end{abstract}


Enhancing the Seeking Safety Group Intervention with Trauma Sensitive Yoga Practice:

A Program Evaluation

by

Thomas Murphy

\begin{abstract}
A Dissertation
Presented in Partial Fulfillment of Requirements for the

Degree of

Doctor of Philosophy

in

Counselor Education and Practice

in

The Department of Counseling and Psychological Services

in

the College of Education and Human Development

Georgia State University
\end{abstract}

Atlanta, GA

2016 
Copyright by

Thomas M. Murphy 


\section{Dedication}

This dissertation is dedicated to my husband, David Gittelman, and to the family and friends that have made this journey possible, most especially Gloria Burkett, Charles Williams, Vinnie Metzger and Diane Levy. 


\section{Acknowledgements}

While it is not possible to acknowledge all the people who have assisted me in my academic career I would like to honor my advisor and mentor Dr. Catharina Chang who has been at the center of my life as a doctoral student. I would like to thank my committee members: Dr. Chang and Dr. Franco Dispenza, co-chairs of this dissertation, Dr. Laura Shannonhouse and Dr. Jane Brack.

I would also like to honor all the faculty and doctoral students who have been so kind in assisting me in pursuit of my academics, teaching and supervision: Dr. Diane Levy, Dr. Jane Brack, Dr. Jonathan Orr, Dr. Brian Dew, Dr. Jeff Ashby, Dr. Melissa Zeligman, Dr. Don Davis, Dr. Dennis Gilbride, Dr. Julie Ancis, Dr. Lindy Parker, Dr. Leslie Stewart, Dr. Julia Whisenhunt, Dr. Maggie Walsh, Dr. Amanda Wolfe, and Dr. Terry Kottman.

This dissertation was a group effort and I thank my research team for all their time and effort. The Positive Impact research team was Dr. Moneta Sinclair and Mr. Rico CurtisDavidson. Ms. Meryl Arnett, yoga instructor for Positive Impact Health Centers, was the inspiration for this study. The Georgia State research team consisted of Ms. Amanda Rumsey and Ms. Nikki Elston.

Finally, I would have had no dissertation, graduation, or body of learning without the kindness and loving support of my doctoral cohort: Rafe McCullough, Cory Viehl, Nedeljko Golubovic and Amanda Rumsey. Together we shall do great things. 


\section{TABLE OF CONTENTS}

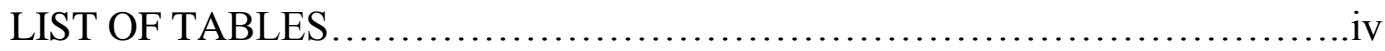

LIST OF FIGURES ..........................................................

1 QUALITATIVE CLINICAL MENTAL HEALTH PROGRAM

EVALUATION: MODELS AND IMPLICATIONS FOR

COUNSELOR EDUCATION .......................................

a. Review.........................................................

b. Program Evaluation............................................ 2

c. Logic Models/Theory of Change ....................................5

d. Evaluation Models for Practitioners......................................

e. Research Education Infusion.......................................12

f. Implications for Counselor Education..............................14

g. Future Directions..................................................

h. Conclusion........................................................ 16

i. References.................................................. 17

2 ENHANCING THE SEEKING SAFETY GROUP INTERVENTION WITH TRAUMA-SENSITIVE YOGA PRACTICE: A PROGRAM

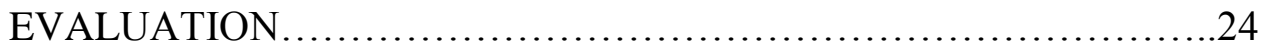

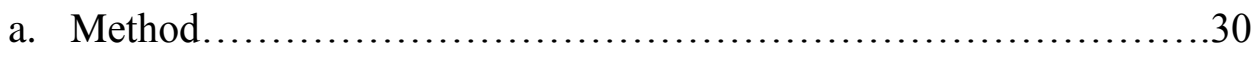

b. Results....................................................... 43

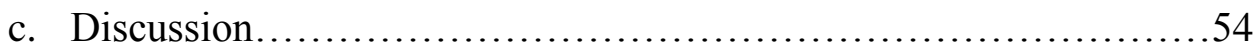

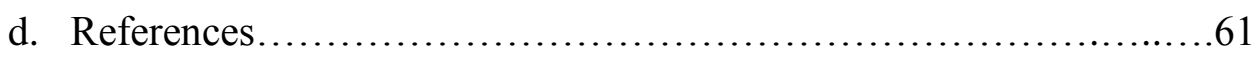

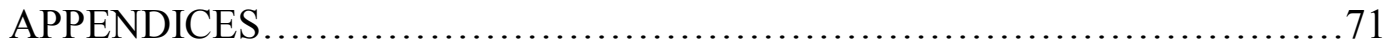




\section{LIST OF TABLES}

Table 2.1: Intensive Outpatient Program Logic Model........................32

Table 2.2: Trauma Demographics based on ITR-R .......................35 


\section{LIST OF FIGURES}

Figure 1.1: Simple Logic Model Template..............................6 


\section{QUALITATIVE CLINICAL MENTAL HEALTH PROGRAM EVALUATION: MODELS AND IMPLICATIONS FOR COUNSELOR EDUCATION}

\section{Review}

\section{Introduction}

Qualitative program evaluation has been used across disciplines to study the experience of participants, outcomes of those experiences, and how programs can be adapted based on those experiences (Patton, 2015a). Qualitative program evaluation has been utilized to improve health programs and services (Tayabas, Leon, \& Espino, 2014), global health management (Kun, Kassim, Howz, \& MacDonald, 2013), metropolitan healthcare strategic planning (Begun \& Kaissi, 2005), and the implementation of yoga programs in high schools (Conboy, Noggle, Frey, Kudesia \& Khalsa, 2013). Qualitative program evaluation and research is expanding within the counseling and mental health profession (Hays, Wood, Dahl \& Kirk-Jenkins, 2016) and has been used to assess the efficacy of Art Therapy (Rowe et al., 2016), PTSD interventions (Cooket al., 2013), Animal-Assisted Therapy (Kemp, Signal, Botros, Taylor \& Prentice, 2014; Stewart, Dispenza, Parker, Chang \& Cunnien, 2014), and paid peer providers in mental health recovery programs (Moran, Russinova, Gidugu \& Gagne, 2013). Nielson (2015) noted that ongoing program evaluation is becoming a necessary practice "essential to counselor survival" (p. 10) as funding for mental health services moves to third-party payers who expect validation of counselor effectiveness. 
While clinicians do not generally conduct research (Murray, 2009), researchers have noted that clinicians can utilize research methodologies within their practice to substantiate innovation in counseling interventions (Lambert et al.,2003; Murray, 2009; Nielson, 2015). Granello and Granello (1998) reported that most practitioners do not engage in research, nor do they believe that research has a significant impact on their counseling practices. However, the opportunity to fine-tune a program must be undertaken when stakeholders are dissatisfied with a program's basic concept or to satisfy accrediting bodies' mandates (Hadley \& Mitchell, 1995).

The purpose of this chapter is to review current conceptualizations of program evaluation, detail program evaluation models, and highlight the importance of program evaluation in counselor education. Because integration of program evaluation and research has been seen as a weakness in counseling and counselor education (Granello, et al., 1998), and research has been identified as a core value of Master's level counselor education (CACREP, 2016; Huber \& Savage, 2009; Kaplan \& Gladding, 2011), a paradigm of incorporating practice-based research and program evaluation design will be explored for implementation in counselor education programs and curriculum. Finally, an argument will be made for increasing focus in counselor education programs on qualitative methods of research that may illuminate best practices in agencies and practices incorporating new interventions or modifying established interventions (Henton, 2012; Lambert, et al., 2003; Lundervold \& Belwood, 2000; Neilson, 2015).

\section{Program Evaluation}

Qualitative program evaluation methodologies promote the democratization of institutions by empowering program stakeholders to take more active roles in analysis (Tayabas et al., 2014). Lincoln and Guba (1986) distinguished the categories of program evaluation, research, and policy analysis as variants of what they refer to as "disciplined inquiry" (p. 547). Program 
evaluation is a process of examining objectives or intents of a program and then determining if the performance of interventions is congruent with those objectives or intents (Hadley \& Mitchell, 1995). Smith (2012) noted that evaluation of programs and interventions is an ethical responsibility of practitioners and contribute professional accountability.

In distinguishing program evaluation from research or policy analysis, Lincoln and Guba (1986) defined evaluation as:

...a type of disciplined inquiry undertaken to determining (merit and/or worth) of some entity - the evaluand - such as a treatment, program, facility, performance, and the like - in order to improve or refine the evaluand (formative evaluation) or assess its impact (summative evaluation). (p. 550).

Furthermore, Lincoln and Guba (1986) observed that research is undertaken to solve a problem while evaluation is undertaken to establish values. Qualitative evaluation of an evaluand can capture a more holistic assessment of interventions and produce meaningful data that directly reflects stakeholders' experiences, which then informs and suggests improvement for programming (Rowe et al., 2016). Qualitative methods, specifically key informant interviews, can provide useful data for strategic planning for mental health practitioners and agencies (Kun, et al., 2013). As Barrett (2013) noted, program evaluation is an involved process used to improve, justify, or further develop programs and interventions. Evidence-based practice continues to be demanded by funders so all viable research methods must be used to affirm the strengths, assets, and value of innovation and organization (Smith, 2010).

While most research and program evaluation is quantitative (Patton, 2015), qualitative inquiry is considered essential to academic inquiry (Morrell, 2010). Stake (2010) noted that quantitative methods focus on "linear attributes, measurements, and statistical analysis" (p. 11) 
and distinguishes qualitative methods as those that rely primarily on human perception and understanding. The open and in-depth explanatory power of qualitative research methods combats the "linear and closed" positivist model (Smith, 2007, p. 181). Experimental or quasiexperimental research, comparing groups receiving interventions versus a control group, can be problematic in mental health settings, particularly if there is evidence that the control group might benefit from the services being withheld (Morell, 2010; Smith, 2010). Placebo designs, often used in medical research, have come into question in mental health studies because often placebo control groups received treatment and were not blocked from the therapeutic process, therefore rendering the idea of "placebo" moot (Wampold, 2001). While this does not preclude quantitative study of mental health counseling, it does reduce the possibility of a classic doubleblind study. Qualitative evaluation provides a diversion from the common perspective that confers superiority to technical and scientific vision over an interpretive, personal analysis of efficacy (Tayabas et al., 2014).

Stake (2010) noted that qualitative studies share the specific characteristics of being interpretive, experiential, situational, and personal. The quality and credibility of qualitative studies are enhanced by the use of triangulation of multiple data sources (Moran et al., 2013) as well as multiple strategies for establishing rigor including reflexivity, member checking, and the use of an external audit before final conclusions are made (Hays et al., 2016). Qualitative evaluations can be designed to maximize credibility through the use of evaluation theory, logic models, and the inclusion of multiple stakeholders (Patton, 2015a). 


\section{Logic Models/Theory of Change}

A logic model or theory of change is a graphic representation of the connection between program inputs, processes and activities, outputs, immediate outcomes, and long term impacts for stakeholders (Patton, 2015a). A logic model's purpose is to communicate the underlying set of assumptions that program stakeholders have about why the program or intervention will be effective or why it may be a solution to an identified problem (Schmitz, Parsons, \& Juvenile Justice Center, 2004). Logic models can be created before a program or intervention is introduced, but they may also be developed after implementation as a guide for both internal and external evaluations (Barrett, 2013). Funnell and Rogers (2011) referred to basic evaluation models as black box evaluation wherein the analysis focuses on what goes into a program and what comes out without details of processes in between or with a focus on long term results. A logic model involves "opening up the black box" (Funnell \& Rogers, 2011, p.4) and assessing individual components along a time line, comparing anticipated outcomes with actual outcomes. Because agencies may be conducting smaller evaluations, or intervention specific evaluations, logic models can be adapted for smaller scale evaluations conducted by practitioners (Astramovich \& Coker, 2007). Logic models are typically divided into four broad categories: pipelines, outcome chains, realist matrices, and narratives (Funnell \& Rogers, 2011). Developing a logic model requires a simple image or graphic, a straightforward approach, and should take up no more than one page (W.K. Kellogg Foundation, 2004). The following is an example of a simple logic model template as described in the literature (Astramovich \& Coker, 2007; Funnell \& Rogers, 2011; Patton, 2015; Smith, 2010; W.K. Kellogg Foundation, 2004): 
Figure 1.1

Simple Logic Model Template

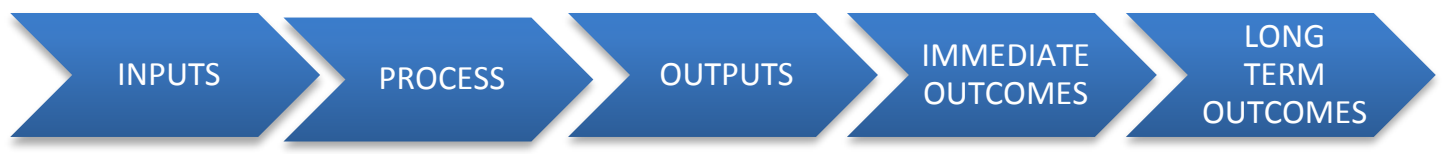

Logic models can be illustrated across axes and with greater or less complexity as dictated by the goals of the program evaluation. An evaluation of a large program (i.e., Intensive Outpatient Addiction Program) would involve multiple layers, each representing parts of the Intensive Outpatient Addiction Program, specific interventions, and detailed outcome data for each of those parts. An evaluation of a single intervention may only detail across one or two dimensions. Stake (2010) recommended analyzing each part for quality and comparing them to the sum of the parts, knowing that final outcomes may not match the quality of any of the individual processes. The evaluation can then proceed based on the evaluation model the evaluators have chosen to frame the evaluation process. While there are a great number of evaluation models (Funnell \& Rogers, 2011), some specific models have proven useful in analyzing mental health counseling, particularly Utilization Focused Evaluation, the Accountability Bridge Model, the Responsive Evaluation Model, the Developmental Model, and Knowledge Based Decision Making.

Utilization-Focused Evaluation, grounded in social justice and cultural awareness, fits research guidelines suggested by the Association of Counselor Educator and Supervisors (Chang, Crethar, \& Ratts, 2010). The Accountability Bridge Model (Astramovich \& Coker, 2007) was designed specifically for counseling research to counter the dearth of counseling research models. The Knowledge Based Decision Making (KBDM) model, which is commonly used in management evaluation (Yim, Kim, Kim, \& Kwahk, 2004), may prove particularly helpful in qualita- 
tive program evaluation because it's format includes levels of triangulation and reflexivity necessary for methodological rigor.

\section{Evaluation Models for Practitioners}

While there are several evaluation models that can be used by counseling practitioners, Utilization-Focused Evaluation, the Responsive Evaluation Model, the Developmental Model, the Accountability Bridge model, and the Knowledge Based Decision Making model offer effective structures for qualitative evaluation of counseling interventions (Patton, 2015a). As noted by Sarja and colleagues (2012), the use of qualitative evaluation models allows an interventionist approach that focuses on development and changes in stakeholders' awareness and shared understanding of program processes. A specific strength found in the use of these models is the ability to capture programmatic and developmental changes over time (Patton, 2015b).

\section{Utilization-Focused Evaluation}

Utilization-Focused evaluation (Patton, 2015b) focuses on pragmatic and situationally specific and adaptive strategies that conform to the Joint Committee of Standards guidelines for program evaluation (Joint Committee on Standards, 2010). Utilization-Focused Evaluation is sensitive to the idea of the utility and actual use of a program by the intended users (Patton, 2015 b). Evaluators adopting Utilization-Focused Evaluation actively involve stakeholders to define the parameters and questions within the evaluation and to clarify the values underlying any program or intervention being evaluated (Ward, Maher, Marcynyszyn, Ellis, \& Pecora, 2011). O'Sullivan (2012) noted that Utilization-Focused Evaluation falls under the theoretical perspective of Collaborative Evaluation and each attempt to maintain the foundational standards of Utili- 
ty, Feasibility, Propriety, Accuracy and Accountability as defined by the Joint Committee on Standards for Educational Evaluation (2010).

Patton (2015b) noted that Utilization-Focused Evaluation is "highly personal and situational" (p.458) in that the evaluator has a personal connection with all the stakeholders involved in the program. The relationship between the evaluator and stakeholders is informed by power and cultural influences within the evaluand (O'Sullivan, 2012). Intended users are more likely to use evaluations if they participate in the process and feel a sense of ownership of the findings and implications (Patton, 2015a; Patton, 2015b). The awareness of culture and context, plus the involvement of stakeholders, interweaves the evaluation with the tenets of social justice seen as imperative in counselor education and research (Chang et al., 2010). Program evaluation that leads to program improvement ultimately benefits program users and stakeholders (Kun et al., 2013; Patton, 2015a; Patton, 2015b).

\section{Responsive Evaluation Model}

The Responsive Evaluation model sets as a goal to reveal the opinions and feelings about an intervention or program by the people most affected by that intervention or program (Stake, 2010). Patton (2015a) noted that the heart of Responsive Evaluation is face-to-face interviews from diverse stakeholders to understand their perspective on programs or interventions. A Responsive Evaluation attempts to understand the process of a program and is not as focused on outcomes of the process (Curran, Christopher, Lemire, Collins, \& Barrett, 2003). Stake (2010) originally listed twelve steps to the evaluation model, which have been modified to six steps: (a) identification of issues or concerns, (b) use of program documents to identify further issues, (c) make direct observation of the program before designing the evaluation, (d) design the evaluation based on the issues that emerged from the first three steps, (e) report information based on 
the direct personal experiences of the stakeholders who participated in the evaluation, and (f) create reports that are specific for the audiences who will read them (Patton, 2015a). The Responsive Evaluation approach has been used to assess the efficacy of medical evaluation (Curran et al., 2003), nursing practice (Barrow, Lyte, \& Butterworth, 2002) and computer education courses (Acat, Kilic, Girman, \& Anagun, 2007). In response to the initial linear and programmatic model introduced by Stake in 1975 (Stake, 2010) subsequent researchers have introduced a constructivist model focused on values-based perspectives (Patton, 2015a).

\section{Developmental Evaluation}

Developmental Evaluation investigates change over time and focuses on emergent change and innovations in organizations (Hadley \& Mitchell, 1995; Patton, 2015a). Qualitative developmental studies focus on the experiences of stakeholders and the research questions are focused on developmental processes and the perception of change over time (Hadley \& Mitchell, 1995). As organizations or programs transform over time evaluation through the developmental model reveals changes in awareness and thinking about innovation. The developmental model is particularly strong for analysis of systems and ongoing adaptations by stakeholders (Patton, 2015a). A weakness in this model, as noted by Sarja, Janhonen, Havukainen, and Vesterinen (2012), is the difficulty in changing stakeholders' ways of thinking about the program and a tendency to confirm that the noted changes have risen organically through the program structure and tend not to be questioned. The developmental model has been used in assessment of teacher effectiveness and innovation (Davis and Zeret, 1984) and project development in higher education (Sarja et al., 2012). 


\section{Accountability Bridge Model}

Astramovich and Coker (2007) developed the Accountability Bridge Model for counselors to provide a framework to be used by individual counselors to assess their effectiveness and impact. The Accountability Bridge Model was conceptualized as a process of providing outcome data and program results to stakeholders as an "accountability bridge between counseling programs and the context of counseling services" (p. 168). The evaluation cycle used in the Accountability Bridge model involves receiving feedback from stakeholders, strategic planning within the organization, development of a needs assessment, and development of service objectives (Astramovich \& Coker, 2007). Stakeholder feedback is essential for developing program goals and adjusting programs and interventions (Ernst \& Hiebert, 2002). The Accountability Bridge Model has been used in evaluation of counselor education programs (Cardaciotto \& Tonrey, 2012) and in school counseling program evaluation (Galassi \& Akos, 2007; Martin \& Carey, 2014). The Accountability Bridge Model allows a system of stages for identifying needs and goals, but has come into some criticism because it is relatively time intensive (Coker, Astramovich, \& Hoskins, 2004).

\section{Knowledge Based Decision Making Model (KBDM)}

Knowledge Based Decision Making (KBDM), according to an extensive literature review, has no history of being used in mental health program evaluation. However, the model has been shown to be an effective tool in School Administration (Doyle, 2002) and management systems (Yim et al., 2004). The underpinnings of KBDM were described as a model utilized in strategic management (Grant, 1996) and as a format for integrating specialist knowledge of stakeholders rather than knowledge creation. Grant (1996) argued that stakeholders have the capacity, through their unique knowledge of corporate systems, to decide if changes need to be made, and 
if so, how to utilize the common knowledge to create a roadmap towards change. Nonaka (1994) identified knowledge as a "flow of messages" (p. 17) by which information is organized or structured.

KBDM involves stakeholders answering a series of questions that define a problem(s), conceptualizing and integrating knowledge, formulating a knowledge model, identify alternatives in the decision-making process, and applying a decision making alternative that arises from the data (Yim et al, 2004). The process bears a strong resemblance to a grounded theory methodology (Charmaz, 2015) in that theory can emerge through qualitative inquiry. The following questions, modified for mental health program evaluation, frame the KBDM process adapted for use in a clinical counseling environment (Yim et al., 2004):

1. What do we know about our stakeholders' needs, wants and preferences that are relevant to the evaluation?

2. What do we know about our resources and strategic position of our stakeholders that is relevant to this evaluation?

3. What do we know about the current realities and evolving dynamics of our stakeholders' environment that is relevant to this evaluation?

4. What are the ethical implications of our choices?

5. What do we wish we knew but don't?

The advantage brought to program evaluation through the KBDM process is the involvement of multiple stakeholders, reflexivity included in the process (e.g., each person utilizing the KBDM model fills out the questions), and triangulation through multiple sources. 


\section{Research Education Infusion}

The American Counseling Association Code of Ethics (American Counseling Association [ACA], 2014) details counselors' responsibilities to promote the welfare of clients (A.1.a.). Counselors are expected to monitor their efficacy (C.2.d.), and utilize interventions that are grounded in theory or have an evidence based foundation (C.7.a.). The Code also specifies that innovative interventions are grounded in theory or have an empirical or scientific foundation (E.7.h.). Counselors who conduct research are expected to conform to pertinent ethical principles (G.1.a.), even when working independently (G.1.c.). Counselors are ultimately responsible for upholding ethical obligations in research for themselves and any members of their research team (G.1.f.). Because the code offers guidelines for independent researchers, counselors who innovate within their practice have an ethical obligation to provide evidence that any innovations are theoretically grounded and are effective (Cardaciotto \& Tonrey, 2012).

The 2016 Council for Accreditation of Counseling and Related Educational Programs Standards (CACREP, 2016) specify that counseling students should have a foundational understanding of research practices and program evaluation as a part of their counselor education programs. However, CACREP does not specify that master's level counseling students should participate in research or have training in conducting research in clinical settings. Murray (2009) has noted that many counseling students do not receive sufficient training in research methodologies to conduct research projects within a clinical practice. In fact, there appears to be a lack of integration of research and practice as a standard in master's level counseling programs, though methods of research classes are a CACREP requirement (Cardaciotto \& Tonrey, 2012).

Practitioner-based research, commonly referred to as action research, focuses on practical issues presenting in a clinical setting (Huber \& Savage, 2009). Training programs that offer stu- 
dents the opportunity to receive hands-on experience with research integrated with clinical practice have shown some success in bridging the research-practice gap (Murray, 2009). Likewise, researchers who show in increased use of methodologies, particularly single-case study and qualitative designs, that are oriented to clinical practice allow practitioners a better opportunity to understand research implications and applicability (Bangert \& Baumberger, 2005).

Granello and Granello (1998) argued that counselor education programs can play a significant role in teaching students the skills to assess their own interventions. They noted that it is important that outcomes research not be relegated to a single class or workshop, but must be integrated within the entire counseling program and related to their clinical work across subjects. Likewise, Murray (2009) has argued for an infusion model that addresses the research-practice gap and argues against the convention that only doctoral students and professors conduct research following the model set by D'Andrea and Daniels (1991) with the incorporation of multicultural issues across the discipline.

The advantage of infusing qualitative research education into master's level counseling programs would help meet the need for evaluation at all levels of clinical practice (Nielson, 2015). Stakeholders, including counseling students and early professionals, would take a leading role in program evaluation and strengthen the transparency between clinical work and creativity in counseling supporting that creativity with evidence-based practice (Tayabas et al., 2014). The research and practice gap that currently exists (Huber \& Savage, 2009; Tayabas et al., 2014) can be narrowed by giving voice to the experiences of clinicians and clients and will inform new directions in counseling (Kun et al., 2013). Given the plethora of resources available to counselors and counselor educators, qualitative research designs could be introduced that would continue to 
be helpful to students after graduation and assist in evaluation at agencies, private practices, and counseling centers (Funnell \& Rogers, 2011; Patton, 2015a; Smith, 2010; Stake, 2010).

\section{Implications for Counselor Education}

While CACREP (2016) requires a research methods course for master's level students, there is no requirement for training in program evaluation. As Astramovich and Coker (2007) noted, there are a lack of counselor-specific evaluation models and suggest that counselor educators focus on creating a continuum between clinical practice and counseling research. Clinical mental health counselors operate on a wellness model and counselor education in research methodologies should be similarly focused (Kaplan, 2010; Nielson, 2015). Murray’s (2009) argument that qualitative research methods be infused into multiple courses in counselor education programs is like the argument that multiculturalism be considered through the entire curriculum. Instilling the idea that any counselor can be a counselor evaluator works to further fulfil the mandate of social justice in counseling by establishing the efficacy of interventions offered to clients (Chang et al., 2012).

Qualitative program evaluation provides methods for counselor educators and counseling students to advocate for clients through substantiation of the efficacy of interventions and intervention adaptation. Client advocacy is essential to the process of counseling (Chang, Barrio Minton, Dixon, Myers, \& Sweeney, 2012) and competence in counseling evaluation is integral to that advocacy by empowering program beneficiaries who have traditionally been excluded from direct research participation (Tayabas et al., 2014). Ezzy (2002) noted that qualitative studies are particularly good at examining meanings without attempting to arrive at absolute answers that apply to all people. Researchers have also noted that positivistic approaches to studying social phenomena are not often applicable to marginalized and under-represented groups (Hays \& 
Wood, 2011). Chang et al. (2012) have reported that professional counselors have a responsibility to generate research to enhance the profession of counseling and to continue to work on improvement of systems for the good of clients and other stakeholders. Chang et al. (2012) have advocated for the inclusion of needs assessments, program evaluations and the skills to interpret studies be included in the syllabuses of required research courses in master's level counselor education programs.

\section{Future Directions}

Considering the dearth of counselors involved in research (Astramovich \& Coker, 2007; Nielson, 2015), studies can be designed to involve master's level students in practicum/internship in program evaluation in their respective sites. Smith (2010) noted that most community agencies do not fund, or underfund, evaluation studies. The CACREP standards (2016) specify that counseling students understand the role of advocacy on behalf of the profession and that program evaluation and research can be considered vital parts of advocacy and social justice (Chang et al., 2012); therefore, infusion of evaluation and research into the practicum/internship experience will lead to a decrease in the current chasm between research and practice (Nielson, 2015).

Future studies should explore infusion of practical evaluation and research into the counselor education curricula. Because counseling students receive instruction on advocacy and social justice, they would bring a fresh perspective on counseling interventions, recognizing monoculturally biased interventions (Kemp, et al., 2014), focus on more holistic interventions (Rowe et al., 2016) and gain a greater understanding of processes supporting evidence-based treatments (Cook et al., 2013). Astramovich and Coker (2007) noted that counseling practice and research 
need not be mutually exclusive activities and that small-scale evaluations can be planned and implemented by practitioners.

\section{Conclusion}

This chapter outlined program evaluation and its current role in the counseling and counselor education fields. Models of program evaluation were introduced, along with the paradigm of the creation of logic models used to prepare for program evaluation. Currently, very few practitioners conduct research and many researchers have forgone clinical practice, leading to a strong dichotomy between counselor educator and counselor practitioner identities. Implications for counselors and counselor educators as well as suggestions for enhancement of counselor education were introduced. It is suggested that evaluation and research be infused within the counselor education process to bridge the perceived gap between clinical practice and practical research. 


\section{References}

Acat, B., Kilic, A., Girmen, P., \& Anagun, S. (2007). The necessity and applicability levels of the courses that are offered in the departments of computer education and instructional technologies (CEIT). Turkish Online Journal of Educational Technology, 6(3), 120-128.

American Counseling Association (2014). Code of ethics. Alexandria, VA: Author.

Astramovich, R. \& Coker, K. (2007). Program evaluation: The accountability bridge model for counselors. Journal of Counseling \& Development, 85(2), 162-172. doi: http://dx.doi.org/10.1002/j.1556-6678.2007.tb00459.x

Bangert, A. \& Baumberger, J. (2005). Research and statistical techniques used in the journal of counseling \& development: 1990-2001. Journal of Counseling \& Development, 83 (4), 480-487. doi: http://dx.doi.org/10.1002/j.1556-6678.2005.tb00369.x

Barrett, N. (2013). Program evaluation: A step-by-step guide. Urbana, IL: Sunnycrest Press.

Barrow, E., Lyte, G., \& Butterworth, T. (2002). An evaluation of problem-based learning in a nursing theory and practice module. Nurse Education \& Practice, 2(1), 55-62. doi: http://dx.doi.org/10.1054/nepr.2002.0043

Begun J. \& Kaissi, A. (2005). An exploratory study of healthcare strategic planning in two metropolitan areas. Journal of Healthcare Management, 50(4), 264-274.

Cardaciotto, L. \& Tonrey, D. (2012). The training, value and reality of master's-level mental health counselors. Journal of Cognitive Psychotherapy: An International Quarterly, 26 (3), 183-195. doi: 10.1891/0889-8391.26.3.183

Chang, C, Crethar, H., \& Ratts, V. (2011) Social justice: A national imperative for counselor education and supervision. Counselor Education \& Supervision, 50(2), 82-87. doi: http://dx.doi.org/10.1002/j.1556-6978.2010.tb00110.x 
Chang, C., Barrio Minton, C., Dixon, A., Myers, J., \& Sweeney, T. (Eds.). (2012). Professional counseling through leadership and advocacy. New York: Routledge.

Charmaz, K. (2015). Constructing grounded theory. Thousand Oaks, CA: Sage.

Coker, J. K., Astramovich, R. L., \& Hoskins, W. J. (2004). Introducing the Accountability Bridge Model: A Program evaluation framework for school counselors. American Counseling Assoc, 46.

Conboy, L., Noggle, J., Frey, J., Kudesia, R. \& Khalsa, S. (2013). Qualitative evaluation of a high school yoga program: Feasibility and perceived benefits. EXPLORE, 9(3), 171-180. doi: 10.1016/j.explore.2013.02.001

Council for Accreditation of Counseling and Related Educational Programs. (2016). CACREP accreditation standards and procedures manual. Alexandria, VA: The Council.

Curran, V., Christopher, J., Lemire, F., Collins, A., \& Barrett, B. (2003). Applications of a response evaluation approach in medical education. Medical Education, 37(3), 256-266. doi: dx.doi.org/10.1046/j.1365.2923.2003.01442.x

D’Andrea, M. \& Daniels, J. (1991). Exploring the different levels of multicultural counseling training in counselor education. Journal of Counseling \& Development, 70 (1), 78-85. doi: http://dx.doi.org/10.1002/j.1556-6676.1991.tb01565.x

Davis, M. \& Zaret, E. (1984). Needed in teacher evaluation: A developmental model for evaluation of teachers, preservice to inservice. Journal of Teacher Education, 35(5), 18-22. doi: dx.doi.org/10.1177/002248718403500505

Doyle, D. (2002). Knowledge based decision making. School Administrator, 59(11), 30-38. 
Ernst, K. \& Hiebert, B. (2002). Towards the development of a program evaluation business model: Promoting the longevity of counseling in schools. Canadian Journal of Counseling, 36, 73-84.

Ezzy, D. (2002). Qualitative analysis: Practice and innovation. New York: Routledge.

Funnell, S. \& Rogers, P. (2011). Purposeful program theory: Effective use of theories of change and logic models. San Francisco: Jossey-Bass.

Galassi, J. P., \& Akos, P. (2007). Strengths-based school counseling: Promoting student development and achievement. Mahwah, N.J: L. Erlbaum Associates.

Granello, P. \& Granello, D. (1998). Training counseling students to use outcome research. Counselor Education \& Supervision, 37 (4), 224-238. doi: dx.doi.org/10.1002/j.15566978.1998.tb00547.x

Grant, R. (1996). Toward a knowledge-based theory of the firm. Strategic Management Journal, 17, 109-123. doi: http://dx.doi.org/10.1002/smj.4250171110

Hadley, R. \& Mitchell, L. (1995). Counseling research and program evaluation. Belmont, CA: Brooks/Cole.

Hays, D., Wood, C., Dahl, H., \& Kirk-Jenkins. (2016). Methodological rigor in Journal of Counseling \& Development qualitative research articles: A 15-year review. Journal of Counseling \& Development, 94, 172-183. doi: dx.doi.org/10.1002/jcad.12074

Henton, I. (2012). Practice-based research and counselling psychology: A critical review and proposal. Counselling Psychology Review, 27 (3), 11-28.

Huber, C. \& Savage, T. (2009). Promoting research as a core value in master's-level counselor education. Counselor Education \& Supervision, 48, 167-178. doi: http://dx.doi.org/10.1002/j-1556-6978.2009.tb00072.x 
Joint Committee on Standards for Educational Evaluation. (2010). The program evaluation standards. Thousand Oaks, CA: Sage.

Kaplan, D. \& Gladding, S. (2011). A vision for the future of counseling: The 20/20 principles for unifying and strengthening the profession. Journal of Counseling \& Development, 89, 367-372. doi: http://dx.doi.org/10.1002/j.1556-6678.2011.tb00101.x

Kemp, K., Signal, T., Botros, H, Taylor, N. \& Prentice, K. (2014). Equine facilitated therapy with children and adolescents who have been sexually abused: A program evaluation study. Journal of Child and Family Studies, 23 (3), 558-566. doi: http://dx.doi.org/10.1007/s10826-013-9718-1

Kun, K., Kassim, A., Howze, E. \& MacDonald, G. (2013). Interviewing key informants: Strategic planning for a global public health management program. The Qualitative Report, 18(10), 1-17. Retrieved from http://nsuworks.nova.edu/tqr/vol18/iss10/3

Lambert, M., Whipple, J., Hawkins, E., Vermeersch, D., Nielson, S, \& Smart, W. (2003). Is it time for clinicians to routinely track patient outcome? A meta-analysis. Clinical Psychology: Science and Practice, 10 (3), 288-301.

Lincoln, Y. \& Guba, E. (1986). Research, evaluation, and policy analysis: Heuristics for disciplined inquiry. Policy Studies Review, 5 (3), 546-565.

Lundervold, D. \& Belwood, M. (2000). The best kept secret in counseling: Single-case (N=1) experimental designs. Journal of Counseling \& Development, 78, 92-102.

Martin, I. \& Carey, J. (2014). Developing of a logic model to guide evaluations of the ASCA national model for school counseling programs. The Professional Counselor, 4(5), 455466. doi: http://dx.doi.org/10.15241/im.4.5.455 
Moran, G., Russinova, Z., Gidugu, V., \& Gagne, C. (2013). Challenges experienced by paid peer providers in mental health recovery: A qualitative study. Community Mental Health Journal, 49(3), 281-291. doi: 10.1007/s10597-012-9541-y

Morell, J. (2010). Evaluation in the face of uncertainty. New York, NY: Guilford Press

Murray, C. (2009). Diffusion of innovation theory: A bridge for the research-practice gap. Journal of Counseling \& Development, 87, 108-116.

Nielson, T. (2015). Practice-based research: Meeting the demands of program evaluation through the single-case design. Journal of Mental Health Counseling, 37 (4), 364-376. doi: http://dx..doi.org/10.17744/mehc.37.4.07

Nonaka, I. (1994). A dynamic theory of organizational knowledge creation. Organization Science, $5,14-37$.

O’Sullivan, R. (2012). Collaborative evaluation within a framework of stakeholder-oriented evaluation approaches. Evaluation \& Program Planning, 35, 518-522. doi: 10.1016/j.evalprogplan.2011.12.005

Patton, M. (2015a). Qualitative research and evaluation methods. Thousand Oaks, CA: Sage. Patton, M. (2015b). The sociological roots of utilization-focused evaluation. The American Sociologist, 46(4), 457-462. doi: http://dx.doi.org/10.1007/s12108-015-9275-8

Rowe, C., Watson-Ormond, R., English, L., Rubesin, H., Marshall, A., Linton, K., Amolegbe, A., ... Eng, E. (2016). Evaluating art therapy to heal the effects of trauma among refugee youth: The Burma art therapy program evaluation. Health Promotion Practice. Doi: $10.1177 / 1524839915626413$. 
Sarja, A., Janhonen, S., Havukainen, P., \& Vesterinen, A. (2012). Modeling in evaluating a working life project in higher education. Studies in Educational Evaluation, 38(2), 5564. doi: 10.1016/j.stueduc.2012.06.001

Schmitz, C., Parsons, B., \& Juvenile Justice Evaluation Center. (2004). Everything you wanted to know about logic models but were afraid to ask. Washington, DC: Juvenile Justice Evaluation Center. Retrieved from http://insites.org/insites_archive/documents/logmod.pdf

Smith, M. (ed.) (2007). Negotiating boundaries and borders: Qualitative methodology and development research. San Diego, CA: Elsevier.

Smith, M. (2010). Handbook of program evaluation for social work and health professionals. New York, NY: Oxford.

Stake, R. (2010). Qualitative research: Studying how things work. New York: Guilford.

Stewart, L., Dispenza, F, Parker, L., Chang, C., \& Cunnien, T. (2014). A pilot study assessing the effectiveness of an animal-assisted outreach program. Journal of Creativity in Mental Health, 9, 332-345. doi: http://dx.doi.org/10.1080/15401383.2014.892862

Tayabas, L., Leon, T. \& Espino, J. (2014). Qualitative evaluation: A critical approach and interpretive complementary approach to improve health programs and services. International Journal of Qualitative Studies on Health and Wellbeing, 9. doi: 10.3402/qhw.v9.24417

W.K. Kellogg Foundation. (2004). Logic model development guide. Battle Creek, MI: W.K. Kel$\operatorname{logg}$ Foundation. Retrieved from http://www.smartgivers.org/uploads/logicmodelguidepdf.pdf

Wampold, B. (2001). The great psychotherapy debate. New York: Routledge. 
Ward, K., Maher, E., Marcynyszyn, L, Ellis, M., \& Pecora, P. (2011). Context matters: Real world and utilization-focused evaluation strategies to support change and improvement in child welfare. Child Welfare, 90(2), 29-47.

Yim, N., Kim, S., Kim, H., Kwahk, K. (2004). Knowledge based decision making on higher level strategic concerns: System dynamics approach. Expert Systems with Applications, 27, 143-158. 


\section{ENHANCING THE SEEKING SAFETY GROUP INTERVENTION WITH TRAUMA-SENSITIVE YOGA PRACTICE: A PROGRAM EVALUATION}

Co-occurring diagnoses of Post-Traumatic Stress Disorder can range from 12\% to 59\% for people requesting services from both inpatient and outpatient addiction programs (Farley, Golding, Young, Mulligan, \& Minkoff, 2004; Lenz, Henesy, \& Callender, 2016; Morgan-Lopez, Saavedra, Hien, Campbell, Wu, \& Ruglass, 2013; Najavits, 2002). Similar percentages apply for clients presenting with trauma-associated difficulties that are not diagnosable as PTSD, or that may have been overlooked as trauma related symptoms (Kessler, Sonnega, Bromet, Hughes \& Nelson, 1995; Strauch, 2001). Individuals presenting with co-occurring PTSD and substance use disorders tend not to respond to conventional treatment that addresses either trauma exposure or substance use disorders alone (Morgan-Lopez et al., 2014; Najavitz, 2012). When both trauma exposure and substance abuse disorders are present, effective treatment can reduce incarceration, homelessness, and relapse (Lenz et al., 2016). Patitz, Anderson, and Najavits (2015) reported that individuals with co-occurring PTSD and substance use disorder may enter high-risk environments when using or purchasing substances, increasing their likelihood of further trauma.

As described in the DSM-5 (American Psychiatric Association [APA], 2015), PTSD is characterized by persistent re-experiencing of the traumatic event, also known as intrusions, persistence of avoidance of people or places associated with the trauma, increased psychological arousal, and persistent numbing of general responsiveness. While the DSM-5 specifies that PTSD symptoms have to have occurred over six months or more, the symptoms may not be explained by substance use or other co-occurring conditions (APA, 2015; Emerson, Sharma, Chaudry, \& Turner, 2009). Because of the prevalence of PTSD and substance abuse as cooccurring disorders, the DSM-5 definition of PTSD is broadened by many researchers to include 
presentations of trauma symptoms without specifically distinguishing those symptoms from symptoms for substance use disorders (Briere \& Scott, 2006; Najavits, 2002) and sometimes referred to simply as traumatic stress response (Foa, Keane, Friedman, \& Cohen, 2009).

Courtois and Ford (2009) noted that trauma survivors attempt to avoid experiencing intense psychological distress and may turn to substance use as an avoidance strategy. Creation of an environment perceived as safe by the clients is paramount to begin effective treatment of cooccurring PTSD and substance use disorder (Briere and Scott, 2006; Najavits, 2002; Patitz et al., 2015). Within a safe, non-threatening environment, clients can be taught skills to reduce trauma symptoms and cravings, and that will allow the client to increase tolerance of strong emotions (Courtois \& Ford, 2009).

Seeking Safety (Najavitz, 2002), an evidence-based manualized group counseling intervention which addresses co-occurring PTSD and substance use disorders, emphasizes selfawareness, life skills, and client empowerment. Researchers have also posited that the use of trauma-sensitive yoga and mindfulness techniques are effective in addressing substance use disorders (Hallgren, Romberg, Bakshi, \& Andreasson, 2014; Telles, Singh, \& Balkrishna, 2012) and responses to trauma (Carter, Gerbarg, Brown, Ware, D'Ambrosio, Dirlea, ..., \& Katzman, 2013; Libby, Reddy, Pilver, \& Desai, 2012; Mitchell, Dick, DiMartino, Smith, Niles, Koenen, \& Street, 2014; Staples, Hamilton, \& Uddo, 2013). While research exists on the efficacy of the Seeking Safety group intervention (Desai, Harpaz-Rotem, Najavits \& Rosenheck, 2008; MorganLopez, et al., 2013; Najavits, 2002; Wolff, Huening, Shi, Frueh, Hoover \& McHugo, 2015) and the use of trauma-sensitive yoga in addiction and other mental health disorders (Halgren, et al., 2014; Posadzki, Choi, Soo Lee, \& Ernst, 2014), a review of current research literature reveals no instances where Seeking Safety and trauma-sensitive yoga have been combined. Since Seeking 
Safety and trauma-sensitive yoga have been found to be effective interventions with clients presenting with trauma, complementary treatment with both interventions could lead to greater efficacy in symptom reduction.

\section{Seeking Safety}

Seeking Safety (Najavits, 2002) is a Cognitive-Behavioral Therapy based manualized group counseling psychoeducation intervention, designed for the treatment of individuals with co-occurring PTSD and substance use symptoms. Seeking Safety has been found to be an effective treatment for multiple populations, including women presenting with substance abuse (Morgan-Lopez, et al., 2013), veterans (Norman, Wilkins, Tapert, Lang \& Najavits, 2010), homeless female veterans with psychiatric disorders (Desai et al., 2008), incarcerated men (Wolff et al., 2015), and problem gamblers (Najavits, Smylie, Johnson, Lung, Gallop \& Classen, 2013). Anderson and Najavits (2014) found that Seeking Safety was also an effective intervention for women with physical disabilities, presenting with PTSD symptoms and substance use. Seeking Safety has also been used effectively with adult survivors of sexual abuse (Ghee, Bolling \& Johnson, 2009). Foa, Keane, Friedman, and Cohen (2009) noted that Seeking Safety is the one of the only co-occurring PTSD models that is established as an empirically supported treatment.

The Seeking Safety manual is designed to be integrated with other treatments for substance abuse and post-traumatic stress (Najavits, 2002). Najvits, Gallop, and Weiss (2006) posit that integrated treatment for co-occurring PTSD and substance use disorders is more effective than treating each disorder separately. Studies have supported the increased effectiveness of an integrated clinical approach to trauma and substance use disorders (Amaro, Chernoff, Brown, Arevalo, \& Gatz, 2007; Boden et al.,, 2011) based on retention and attendance in treatment, reduction in PTSD symptoms (Patitz, Anderson \& Najavits, 2006), and reduction in substance use 
(Boden et al., 2011; Cocozza et al., 2005). Proactive targeting of commonly co-occurring disorders is an exception from most treatment protocols that generally identify either PTSD or substance use disorders separately, and very little focus has been placed on the treatment of concomitant presentation (Foa et al., 2009).

The primary strategies of the Seeking Safety intervention are to (a) instill a sense of safety, (b) generate self-respect, (c) develop coping skills to replace substance use, (d) create a better future, (e) develop trust, (f) identify safe people who can be helpful in recovery, (g) learn selfcare, $(\mathrm{g})$ become substance free while addressing past traumas, (h) try new things, and (i) learn to be persistent in the face of adversity (Najavits, 2002). The program manual consists of 25 group sessions that do not need to be followed in order. Each session includes an agenda, client handouts, quotations for the lesson, text on how to deal with tough clients, and points out possible areas of countertransference for the counselor. While the treatment sessions are manualized, clients control the direction each session takes with the support and guidance of the clinician. At the end of each session, clients are encouraged to indicate their commitment to change and are asked to identify a community resource that might be helpful in the process. Because the manual is standardized with a lesson plan for each subject no additional training is required for clinicians using the intervention (Najavitz, 2002).

Seeking Safety is designed to support clients in establishing and increasing their sense of personal safety while concurrently addressing trauma and substance use concerns. Najavits' (2002) focus is placed on prevention of further problems (e.g., HIV exposure, dangerous relationships) and addressing suicidal ideation and self-harm. The group process is designed to remain psychoeducational and individual traumas are not discussed to maintain the safety of participants and the prevention of vicarious trauma. 


\section{Trauma-sensitive Yoga}

Yoga has been defined as "a part of Ayurvedic medicine that can consist of one or more of the following: specific postures, breathing exercises, body cleansing, mindfulness meditation, and lifestyle modifications" (Posadzki \& Ernst, 2011, p. 1). Trauma-sensitive yoga is a form of yoga "designed to directly address symptoms associated with traumatic exposure" (West, Liang, \& Spinazzola, 2016, p. 8) by creating a safe environment using modified yogic techniques that include reduction or elimination of corrective touch, focus on client choice and language inviting the clients to try rather than to accomplish specific actions (Emerson, et al., 2009). Clinicians have successfully utilized traditional and trauma-sensitive yoga practice in the treatment of various psychiatric conditions (Da Silva, Ravindran, \& Ravindran, 2009; Shannahoff-Khalsa, 2004), including anxiety disorders (Kirkwood, Rampes, Tuffrey, Richardson, \& Pilkington, 2005), eating disorders (McIver, O’Halloran, \& McGartland, 2009), and insomnia (Sarris \& Byrne, 2011).

Researchers recently conducted a meta-analysis of the use of yoga in the treatment of substance use disorders and found that various types of yoga (i.e., Iyengar, Nidra, Hatha) led to significantly more favorable outcomes than various control interventions (Halgren et al., 2014; Posadzki \& Ernst., 2014). Likewise, yoga has been found to be an effective adjunct treatment for trauma from domestic abuse (Clark et al., 2014), women diagnosed with PTSD (Mitchell et al., 2014) veterans diagnosed with PTSD (Staples, Hamilton, \& Uddo, 2013), and childhood survivors of sexual abuse (Lilly \& Hedlund, 2010). Positive effects on wellbeing have been shown to increase with the use of yoga (Caplan, Partillo, \& Seely, 2013). A decrease in trauma related dissociation has been evidenced by the use of traditional yogic techniques including meditation, relaxation, and physical postures (Emerson, et al., 2009; Waelde, 2004). Van der Kolk and colleagues (2014) found that trauma-sensitive yoga used in the treatment of women with PTSD sig- 
nificantly reduced symptomology comparable to other evidence-based psychotherapeutic and psychopharmacological interventions.

\section{The Present Study}

While Yoga has been combined with other treatment modalities like individual therapy with a CBT focus and/or the prescription of medication for substance use disorders (Hallgren et al., 2014; Posadzki et al., 2014) and PTSD (Carter et al., 2013; Libby, Reddy, Pilver, \& Desai, 2012), to date there has been no research on the combination of a trauma-sensitive Yoga intervention included in Seeking Safety. There is strong evidence that Yoga can be an effective adjunct treatment in other settings (Hallgren et al., 2014). Therefore, adding Yoga to one of the strongest empirically supported group treatment protocols for co-occurring addiction and trauma (Foa et al., 2009) would seem a logical extension of practice.

Utilizing archival data collected in 2016, this current study is a qualitative UtilizationFocused Program Evaluation examining the effectiveness of the Seeking Safety (Najavits, 2002) addiction and trauma group intervention enhanced with a trauma-sensitive yoga practice within an intensive outpatient addictions program at a mental health agency in a large Southern city. This qualitative single-case study evaluation explored outcomes of the combined interventions by documenting how the stakeholders in this program experience the interventions under realworld conditions. Because the interventions are a part of a larger intensive outpatient addictions program an evaluation based on experimental design (withholding treatment from a control group) would be incongruent to the mission of the program (Nielson, 2015) therefore, a qualitative program evaluation was deemed more appropriate. The research question of this qualitative program evaluation is what is the efficacy of a Yoga-enhanced Seeking Safety group intervention as a part of a comprehensive addiction program? 


\section{Method}

\section{Research Methodology}

Program evaluation is defined as a distinct type of disciplined inquiry intended to determine the merit or worth of an intervention, program, or facility (Lincoln \& Guba, 1986). Evaluation of treatments or programs allows a continuum to be formed between research and practice to improve counseling services and to find evidence that current services are effective (Astramovich \& Coker, 2007). Practice-based research takes place in the environment where counseling occurs (Neilson, 2015), and often funding of programs and services hinges on the ability of an agency or practice to demonstrate successful outcomes to funding agencies (Astramovich \& Coker, 2007). Continuing evaluation of programs and interventions can be considered best practice in strategic planning for agencies and practices that utilize innovative or adapted interventions with clients (Begun \& Kaissi, 2005). While evaluation can be time consuming and complex, the results can be used to improve and justify developments in mental health programs (Barrett, 2013). Clinicians and other stakeholders in mental health agencies may be asked to conduct evaluations, particularly when resources are limited, and accountability is required from funders (Smith, 2010). Morrell (2010) notes that evaluation is "intimately bound up with innovation" (p. 9) because evaluation itself is considered innovation.

Utilization-Focused evaluation (Patton, 2015b) focuses on pragmatic, situationally specific and adaptive strategies that conform to the Joint Committee of Standards guidelines for program evaluation (Joint Committee on Standards, 2010). Utilization-Focused Evaluation is informed by the idea of the utility and actual use of a program by the intended users (Patton, 2015 b). Evaluators adopting Utilization-Focused Evaluation actively involve stakeholders to define the parameters and questions within the evaluation and to clarify the values underlying any pro- 
gram or intervention being evaluated (Ward, Maher, Marcynyszyn, Ellis, \& Pecora, 2011).

O'Sullivan (2012) noted that Utilization-Focused Evaluation falls under the theoretical perspective of Collaborative Evaluation and each attempt to maintain the foundational standards of Utility, Feasibility, Propriety, Accuracy and Accountability as defined by the Joint Committee on Standards for Educational Evaluation (2010).

Patton (2015b) noted that Utilization-Focused Evaluation is "highly personal and situational" (p.458) in that the evaluator has a personal connection with all the stakeholders involved in the program. The relationship between the evaluator and stakeholders is informed by power and cultural influences within the evaluand (O'Sullivan, 2012). Intended users are more likely to use evaluations if they participate in the process and feel a sense of ownership of the findings and implications (Patton, 2015a; Patton, 2015b). The awareness of culture and context, plus the involvement of stakeholders interweaves the evaluation with the tenets of social justice seen as imperative in counselor education and research (Chang et al., 2010). Program evaluation leading to program improvement ultimately benefits program users and stakeholders (Kun et al., 2013; Patton, 2015a; Patton, 2015b).

Program evaluation is often framed by a logic model developed by the organization being evaluated (Patton, 2015a). A logic model's purpose is to communicate the underlying set of assumptions that program stakeholders have about why the program or intervention will be effective or why it may be a solution to an identified problem (Schmitz, 2004). Logic models can be created before a program or intervention is introduced, but they may also be developed after implementation as a guide for both internal and external evaluations (Barrett, 2013). The following is a logic model created using a pipeline and outcomes chain (Funnell and Rogers, 2011) to reflect the steps and intended outcomes of this intervention. 
Table 2.1

Intensive Outpatient Program Logic Model

\begin{tabular}{|c|c|c|c|c|}
\hline Inputs & Activities & Initial Outcomes & $\begin{array}{l}\text { Intermediate Out- } \\
\text { comes }\end{array}$ & Ultimate Outcomes \\
\hline $\begin{array}{l}\text { Intensive Outpatient } \\
\text { Addiction Program - } \\
\text { ASAM Level II }\end{array}$ & $\begin{array}{l}\text { Seeking Safety Group } \\
\text { Counseling Interven- } \\
\text { tion/Trauma-sensitive } \\
\text { Yoga }\end{array}$ & $\begin{array}{l}\text { Increase in coping } \\
\text { strategies }\end{array}$ & $\begin{array}{l}\text { Increase in life } \\
\text { skills/working/reduci } \\
\text { ng time at agen- } \\
\text { cy/integration back } \\
\text { into social milieu. }\end{array}$ & $\begin{array}{l}\text { Successful integra- } \\
\text { tion into social mi- } \\
\text { lieu. }\end{array}$ \\
\hline Individual Counseling & $\begin{array}{l}\text { Education on addiction } \\
\text { and trauma. CBT skills } \\
\text { training. }\end{array}$ & $\begin{array}{l}\text { Reduction of activa- } \\
\text { tion using intentional } \\
\text { breathing/scrunching } \\
\text { toes/stretching }\end{array}$ & $\begin{array}{l}\text { Continued interaction } \\
\text { with } 12-\text { Step/support } \\
\text { groups/IOP Cohort }\end{array}$ & Maintain Sobriety \\
\hline $\begin{array}{l}\text { Drug/Alcohol Moni- } \\
\text { toring }\end{array}$ & $\begin{array}{l}\text { Participation and obser- } \\
\text { vation of yoga practice. } \\
\text { Learning interventions to } \\
\text { reduce trauma symptoms }\end{array}$ & $\begin{array}{l}\text { Cognitive under- } \\
\text { standing of activa- } \\
\text { tion/craving }\end{array}$ & $\begin{array}{l}\text { Practice establishing } \\
\text { healthy boundaries. }\end{array}$ & $\begin{array}{l}\text { Integration into safe } \\
\text { social system. }\end{array}$ \\
\hline $\begin{array}{l}\text { Group Counseling } \\
\text { Seeking Safety/Yoga } \\
\text { Anger Management } \\
\text { Process Group } \\
\text { Healthy Relationships }\end{array}$ & $\begin{array}{l}\text { Linking somatic yoga } \\
\text { process to addiction and } \\
\text { trauma education. Intro- } \\
\text { duction of somatic } \\
\text { skills/recognizing activa- } \\
\text { tion/tools for reducing } \\
\text { activation/intentional } \\
\text { breathing and movement. }\end{array}$ & $\begin{array}{l}\text { Intentional reduction } \\
\text { of activation using } \\
\text { tools from program. }\end{array}$ & $\begin{array}{l}\text { Continued use of } \\
\text { yoga and trauma } \\
\text { coping skills. } \\
\text { Maintenance of so- } \\
\text { briety. Participation } \\
\text { in continuing care. }\end{array}$ & $\begin{array}{l}\text { Increased sense of } \\
\text { control over life. } \\
\text { Physical and mental } \\
\text { health maintenance. }\end{array}$ \\
\hline \multicolumn{5}{|l|}{ Housing } \\
\hline \multicolumn{5}{|l|}{$\begin{array}{l}\text { Primary Care/Case } \\
\text { Management }\end{array}$} \\
\hline $\begin{array}{l}\text { Life Skills train- } \\
\text { ing/Money Manage- } \\
\text { ment }\end{array}$ & & & & \\
\hline
\end{tabular}

\section{Original Data Source}

Original data used for this program evaluation study consisted of archival interviews of outpatient addiction clients, a client focus group and individual interviews with clinical staff members. Data were originally collected by two clinical staff members of a community health center offering behavioral health and addiction services to HIV positive and recently incarcerated clients in a large southern city. The data collected were for use in evaluating the efficacy of combining the Seeking Safety group intervention with the addition of a trauma-sensitive yoga 
component. The data collection was conducted with approval from the Institutional Review Board (IRB) of the participating agency. The study was overseen by a Counseling Psychologist employed by the organization. The data collected were from individual interviews and focus groups. Key stakeholders were individually interviewed about their experiences with the Seeking Safety intervention enhanced with a trauma-sensitive yoga practice. Key stakeholders included clients, clinicians, and the administrator overseeing the intensive outpatient program. Interviews were conducted by clinicians who were not directly involved in the intervention, each participant received an Informed Consent (see Appendix A) and were specifically instructed that they were not required to participate in the study.

Participants. The participants for this study were key stakeholders in the Intensive Outpatient Addiction Program in community mental health agency located in a large southern city. Stakeholders included clients in the Intensive Outpatient Addiction Program or Continuing Care Program $(n=14)$, facilitators of the Seeking Safety group $(n=2)$, the trauma-sensitive yoga instructor $(n=1)$ and an administrator for the addictions program $(n=1)$. All participants were volunteers, and all participants received an Informed Consent detailing their rights as participants in an evaluation study.

Procedure. Qualitative program evaluation includes multiple stakeholders for the collection of data (Lincoln \& Guba, 1986; Patton, 2015a). This qualitative sampling strategy allowed in-depth exploration from key stakeholders representing fundamental populations of the program and intervention (Barry, Abraham, Weaver, \& Bowersox, 2016; Patton, 2015b). Individual client interviews were conducted with fourteen participants, ages ranging from $24-61$ years $(M=42$ years). Eight of the participants identified themselves as Black or African American and six participants described themselves as White. Clients were asked about their sexual orientation and 
gender identity with eight participants identifying as Gay and six participants identifying as Straight or Heterosexual. Nine clients identified their gender identity as cisgender male, four as cisgender female and one as transgender female. Six of the clients claimed no religious affiliation and eight clients affiliated with Christian denominations. Five clients noted that they were participating in the Intensive Outpatient Addictions Program while nine clients noted that they were participating in Continuing Care.

A focus group $(n=15)$ also participated in a semi-structure interview conducted by a staff member who is a doctoral level counselor educator. Some of the participants who were interviewed individually also participated in the focus group. The focus group participants' age ranged from 24 years to 61 years old $(M=46.6)$. The focus group had 11 participants who identified as male, three as female, and one as transgender with five participants racially identifying as White and 10 identifying as Black or African American.

Four semi-structured interviews were conducted with staff members. The director of the program identified as a 61-year-old Black, heterosexual, cisgender man. The trauma-sensitive yoga instructor identified as a 34-year old, White, heterosexual cisgender woman. Both clinicians interviewed identified as White, heterosexual, cisgender women, ages 25 and 24.

Measures. Each individually interviewed participant provided demographic information and completed Briere's (2004) Initial Trauma Review - Revised (ITR-R) survey (See Appendix B) to assess lifetime trauma exposure. All the clients identified significant exposure to trauma both before age 18 and after age 18 . Table 2.2 details the traumatic events and the levels of trauma that were experience by the clients. 
Table 2.2

Trauma Demographics based on ITR-R

Trauma Experienced Before Age 18.

\begin{tabular}{cccc}
$\begin{array}{c}\text { Trauma theme experienced } \\
\text { by clients before age } 18 .\end{array}$ & $\begin{array}{c}\text { Total clients en- } \\
\text { dorsing theme. }\end{array}$ & $\begin{array}{c}\text { Clients felt very } \\
\text { afraid, horrified or } \\
\text { helpless. }\end{array}$ & $\begin{array}{c}\text { Client felt they } \\
\text { might be injured } \\
\text { or killed. }\end{array}$ \\
\hline
\end{tabular}

Punished in a way that left

9

9

7

bruises, cuts, or made client bleed.

Did anyone 5 or more years

9

6

5

older ever do something

sexual to client.

Did anyone less than 5 years

2

1

1

older ever do anything sexual against client's will.

Ever involved in a serious

6

5

4

automobile accident.

Client saw someone get

6

6

6

killed or seriously injured. 


\section{Trauma Experienced Since Age 18}

\begin{tabular}{|c|c|c|c|}
\hline $\begin{array}{l}\text { Trauma theme experienced by } \\
\text { clients after age } 18 \text {. }\end{array}$ & $\begin{array}{l}\text { Total clients } \\
\text { endorsing } \\
\text { theme. }\end{array}$ & $\begin{array}{l}\text { Clients felt very } \\
\text { afraid, horrified, or } \\
\text { helpless. }\end{array}$ & $\begin{array}{l}\text { Client felt they } \\
\text { might be injured } \\
\text { or killed. }\end{array}$ \\
\hline
\end{tabular}

Something sexual was done

11

against client's will.

Client was slapped, hit, or nearly strangled by sexual or marital partner.

Client was physically attacked, assaulted, stabbed, or shot by someone not in a sexual relationship.

Ever involved in a serious automobile accident.

Ever involved in a serious fire, earthquake, flood, or natural disaster.

Ever been beaten, assaulted, or shot by police or another law enforcement official.

Ever seen someone killed or seriously hurt.

11

8

4

1

4

6
11

8

10

10

8

8
2

1

3

6
2

1

3

5

Because analysis of the data is based on archival documents, the results of the Briere Initial Trauma review are illustrative and not intended for quantitative analysis. All interviews were anonymized before being released to the research team, and a correlation between trauma exposure and specific individuals was not possible for this study. However, these data indicate that the participants in the Intensive Outpatient Addiction Program at the agency present with high levels of trauma exposure that may or may not correlate with substance use. 
The researchers then conducted a semi-structured interview focusing on clients' experiences in the yoga-enhanced Seeking Safety intervention (see Appendix C). Participants were assigned a participant number, and the list of participants' names was kept in a separate locked office inaccessible to the principle investigator to maintain confidentiality of the participants. All interviews were recorded and transcribed with any identifying information deleted.

Interview questions were developed through an iterative process. The principle investigator developed the initial draft questions, and the research team responded with feedback and comments. Interview guides were created for individual client interviews, a client focus group, and facilitator interviews. The interview guide allowed the interviewers to approach data collection in a systematic way while allowing for additional inquiry based on client response (Patton, 2015a). The principle investigator and the interviewers met in person after three interviews were conducted to discuss and revise the research questions as themes emerged from individual interviews. The principle investigator and the interviewers then met after interviews 7 and 10 for further review of questions.

A focus group was held after individual interviews had been conducted. Questions for the focus group were developed by the iterative process by all the investigators meeting to design the semi-structured interview questions. Based on feedback and responses received from some participants indicating yoga was perceived through a racial and gendered lens, members of the research team added questions specific to cultural background and experiences with yoga. Some participants, particularly those who identified as Black or African American, seemed to perceive yoga as a "White" activity, which the research team decided deserved further exploration. Participants responded to questions (see Appendix E) asked by a member of the agency research team. Participants received an Informed Consent (see Appendix D) and were told specifically 
they were not required to participate, that their comments would be confidential, and that they would have no negative consequences if their opinions towards the intervention were negative. The focus group was recorded and transcribed with any identifying information removed. All interviews were transcribed verbatim. After transcriptions were completed, the interviews were placed in a secure file on a computer in a locked office until the second phase of the evaluation received university IRB approval.

Evaluation Team. The original evaluation team who collected the data consisted of:

- The principle investigator, a Counselor Education and Practice doctoral student who identifies as a White, cisgender, gay male. The principle investigator is also a part-time clinician at the agency where the research was conducted.

- A doctoral level counselor educator who is a program manager at the agency and who identifies as a Black, cisgender, heterosexual female. This member of the research team had limited exposure to Seeking Safety, but never with the yoga enhancement.

- A Counselor Education and Supervision doctoral student employed by the agency as a supervisor who identifies as a Black, cisgender, gay male. This member of the research team had no exposure to Seeking Safety, but is an experienced clinician working with clients presenting with substance use disorders.

Evaluation Team Process. The research team met before the evaluation began to address personal subjectivities and biases. A core principle of qualitative research is that the researcher acknowledges his or her perspectives, power positions, and subjectivity that may have influence on the approach to the research and research findings (Charmaz, 2008). Because this evaluation was conducted by key stakeholders, acknowledgement of subjectivities was a necessary first step for development of trustworthiness. Patton (2015) noted that a philosophical belief 
in qualitative inquiry is a prime component of credibility and that qualitative rigor is based on the quality of the observations of the researcher. For this evaluation, the research team noted that they were each counselor educators who had actively participated in qualitative research in the past. All the members of the evaluation team identified the Biopsychosocial Model of addiction - that addiction is a process influenced by genetics and the environment. One member of the evaluation team noted that he started his career informed by the medical model of addiction that it is a disease - but moved in time to the Biopsychosocial model.

\section{Data Analytic Plan for Present Study}

Research Team. The archival data generated by the original evaluation team were transferred to the Principal Investigator of this study for coding and analysis. All data were deidentified. The research team who coded the interviews and developed the code book met in advance to discuss biases and positionality regarding trauma and yoga. The research team who coded the data and developed the codebook consisted of:

- The principle investigator, a Counselor Education and Practice doctoral candidate who identifies as a White, cisgender, gay male. The principle investigator is a part-time clinician at the agency where the study was conducted and formerly facilitated the Seeking Safety group enhanced with trauma-sensitive yoga. The principle investigator has presented at academic conference with the yoga instructor on the use of trauma-sensitive yoga in addiction programs and actively participated during the yoga portion of the Seeking Safety session and recognizes his bias in favor of Seeking Safety enhanced by trauma-sensitive yoga and therefore did not participate in any of the interview process with clients. However, the principle investigator did interview other facilitators involved in the program believing he could successfully bracket his biases during those conversations. 
- A Counselor Education and Practice doctoral student who identifies as a White, cisgender female whose sexual orientation is fluid. She has incorporated yoga into her own life and views it to ground herself, become more centered, and mindful throughout the day. She noted that she views yoga as an individual practice and that "getting it right" is important. She believes yoga, physical exercise and grounding leads to personal integration and the opening of the spiritual self. She sees yoga as mostly White, but not mainstream. Her work as a counselor has been primarily in academic advisement and she has not actively provided clinical services to addiction or trauma clients.

- A Counselor Education and Practice doctoral student who identifies as a White, cisgender, heterosexual cisgender female. As a clinician, this investigator utilized yoga as a part of Wilderness Therapy but is not systematically trained as a yoga instructor. She noted that she sees yoga as an activity primarily conducted by White people of a higher socio-economic status than she is. She notes a bias towards integrating her own CBT theoretical orientation with physical activity believing efficacy of interventions is increased through movement and somatic experience. As a middle school counselor, she has experience working with both trauma and addictions but does not integrate yoga into her work at school.

Data Analysis Procedures. The verbatim archival transcripts of participant interviews, the archival transcript of the focus group and the archival interviews with clinicians were coded separately by members of a research team (Patton, 2015a). After initial coding the research team met for comparison analysis (Hays \& Singh, 2011), and the development of the initial codebooks. Codes were then compared and categorized by themes generated by client participant interviews and by the clinician interviews and developed into two separate codebooks. Each series 
of themes were then collapsed based on convergence into categories and sub-categories (Patton, 2015a), generating final codebooks for each set of interviews.

Quality and Trustworthiness. The American Counseling Association (ACA) Code of Ethics (ACA, 2014) mandates that independent researchers and counselors who innovate within their practice have an ethical obligation to provide evidence that any innovations are theoretically grounded and are effective (Cardaciotto \& Tonrey, 2012). A primary concern in research is the impact on trauma survivors when they are asked about their traumatic experiences (Griffin, Resick, Waldrop, \& Mechanic, 2003). Stake (2010) noted that the risks of social research are rarely physical, but tend to be cognitive and emotional. Internal review boards are frequently concerned that trauma research may cause harm to participants and have been hesitant to extend permission to conduct research in consideration for participant welfare (Edwards \& Sylaska, 2016; Jaffe, DiLillo, Hoffman, Haikalis, \& Dykstra, 2015). Researchers have shown that helplessness or lack of control are central experiences for trauma survivors (Pearlman \& Caringi, 2009). However, trauma researchers have consistently reported that while participants may have some initial discomfort during the collection of research they generally viewed the research as both interesting and valuable (Griffin et al., 2003). These results have been supported in specific populations including sexual assault survivors (Neilson, Hansen, Elklit, \& Bramsen, 2016) and lesbian and gay survivors of intimate partner violence (Edwards \& Sylaska, 2016). To protect participants in this study, an Informed Consent form was provided to participants explaining that some of the questions asked might cause some discomfort, that the participant could end participation at any time and that clinical mental health counselors were available if the participant felt a need to process vicarious traumatization. Bogdan and Biklen (2007) noted that research involving people over whom the researcher may have a degree of authority could be problematic. 
In this study, to further protect the participants, research team members who collected data did not have a clinical role with any of the participants.

Because qualitative evaluation can be conducted from myriad theoretical foundations, a uniform trustworthiness standard is neither possible nor is it needed (Kline, 2008; Patton, 2015a). Flexibility in qualitative evaluation is necessary (Patton, 2012), but trustworthiness arises from intentionality with the elements of credibility, transferability, dependability and confirmability (Lincoln \&Guba, 1985). Patton (2012) notes that in Utilization-Focused program evaluation trustworthiness is enhanced by the transparent nature of data collection and the feedback of individual participants on the evaluation findings.

The current study utilized the following strategies for developing trustworthiness based on strategies gathered by Hays et al. (2016):

1. Prolonged engagement. The research team was actively engaged in the agency and the agency culture.

2. Triangulation: The evaluation used multiple forms of evidence to support conclusion with multiple data methods (interviews and focus groups), subjectivity statements from the research team, and confirmation from participants that the data collected were accurate. All coding of data was conducted by three members of the research team.

3. Reflexivity: The researcher kept ongoing memos describing assumptions and biases throughout the research process. Changes in data collection, interview questions and analysis were undertaken through an iterative process among the investigators.

4. Thick description: The research processes were detailed and the outcomes can be applied to findings and are sufficient to replicate the study. 
5. External audit: The research process was reviewed by an auditor who did not participate in any of the prior data collection or analysis. The auditor reviewed all memos, codebooks, data, and data analysis and was asked to document and confirm that the research team followed an established qualitative protocol (Guba \& Lincoln, 1989). The auditor was selected based on her experience with both qualitative and quantitative research and her position as an established researcher in Counseling Psychology.

6. Negative case analysis: All cases were examined, and the research team looked for themes that disconfirmed unanimity in the study, (i.e. the lack of belief in the efficacy of one or both interventions.) Participant 10 was a detractor towards the yoga practice:

... I didn't like it, well, I still don't really like it, I felt like I didn't really see the benefit from it. Um, it's just not my thing. To be quite honest, um, I'm more into the meditation kind of thing. I know what the yoga purpose is. So I understand that can work for other people, it just doesn't work for me.

\section{Results}

The research team identified two primary themes derived from the archival client interviews and three primary themes derived from the clinician interviews. The themes derived from the clinician interviews were: (a) Intervention Process, (b) Cultural Factors, and (c) Intervention Outcomes. The themes derived from the client interviews were (a) Client Response to Intervention and (b) Yoga as a Bridge Between Trauma and Addiction. Three subthemes were identified within Client Response to Intervention (a) Client use of yoga, (b) Prior beliefs about yoga, and (c) Partnered yoga. 


\section{Clinician Themes}

Intervention Process. The clinical staff related a number of objectives for the combination of Seeking Safety and trauma-sensitive yoga. A primary objective was to create a "safe space" for exploration and learning. They all noted that yoga introduces concrete techniques and increased the skill set clients could use to reduce activation and cravings. With those additional skill sets they believed clients would be able to link physical experience to their experiences in recovery and create a synergy between the cognitive aspects of the Seeking Safety intervention and the somatic aspects of trauma-sensitive yoga. Both of the clinicians leading the group noted that they wanted to reduce the power differential between the clients and clinicians and allow the clients to see the clinicians participate, and struggle, in the yoga portion of the intervention.

Both the yoga instructor and the clinical director described an objective of increasing "buy in" from the clients for both Seeking Safety and trauma-sensitive yoga. The yoga instructor noted that after introducing the concepts of trauma and addiction and their relation to the yoga practice the clients became more willing to participate: "Right off the bat there was a change in the questions that I got and the feedback that I got and the willingness to participate changed instantly." The director reported that adding yoga to the Seeking Safety group "enhanced the clients' buy-in into the entire process and their willingness to take some responsibility for their process in terms of yoga and PTSD and managing their symptoms." The yoga instructor noted that she coordinated with the facilitators of the Seeking Safety group in order to adapt her program to the chapter that was being discussed that week:

... I know what the subject is for that week, so for example, if the subject was compassion what I would emphasize more was, you know, how are you choosing to move and take care of your body ... then whoever's co-leading with me will introduce the topic, 
say compassion, have that discussion, and then I can come back in somewhere in the middle and say how did that practice relate?

In reviewing the intentional reduction of the power differential between clinician and clients, clinician 2 noted: "how different this felt than other psychoeducation groups because we were all doing yoga together." Clinician 1 said that she believed that it made "a big difference" that the facilitators also participate in the yoga." Both clinicians reported that their participation in the yoga exercises increased the level of communication they experienced with the clients and, they believe, clients' willingness to participate in all elements of the intervention.

The yoga instructor was trained specifically in trauma-sensitive yoga practices. These practices include keeping the lights on, not walking behind people, avoiding touching the clients and asking permission should she feel that touch is necessary. She noted that she did not correct the clients' posture or techniques “even if they're doing something totally different than what I said, unless it looks like there's about to be an injury." She noted that tying the somatic elements of yoga with the somatic elements of trauma are fundamental to her practice within the Seeking Safety group:

... my goal is to get them to feel something safe in their body because so often it goes from 'this is unpleasant' to totally shutting down ... so if there can be just the slightest bit of discomfort they don't have to shove it down and at least it gets on the spectrum of feeling again and we can work on getting stronger and stronger sensations...... the idea is simply that you can have an experience in your body and you can have it in a way that's very present and mindful and safe.

Because one of the objectives of combining Seeking Safety was to create a safe space to explore uncomfortable or challenging feelings, partnered yoga practice was introduced so clients 
could practice poses by physically supporting each other. The yoga instructor reported that the clinicians had been working with a specific group of people for some time "and we knew them and they knew us and trusted us" and felt partnered yoga related to the topic of boundaries. She noted that when the group was covering boundaries, partnered yoga would give clients practice in saying yes or no to something that felt uncomfortable. For each pose, clients had to ask permission to touch their yoga partner and for each pose the yoga partner had permission to say yes or no to the invited touch. Clinician 2 reported:

... I loved the partnered yoga . . it built relationships and rapport within the group and among the pairs .. I also thought it was valuable for the people who didn't participate and who watched ... the experience of trusting another person with their bodies and I think that was the first step that some people needed before they were able to actually do it themselves.

In introducing a new and effective skill set for clients, the yoga instructor adapted her strategy to offer interventions clients can practice any time or any place. She noted that "what I try to do is be aware of offering things that they can do in one minute, anywhere, and get that sense of grounding, of the presence of safety." She will have the clients scrunch their toes, make their fist into a ball, count their breaths and connect it to "your body, what you' re feeling is always important, regardless, it's always important." Clients are not only able to link physical experiences with recovery; they can utilize simple exercises in the moment to reduce activation related to cravings and trauma related symptoms.

Cultural Factors. In the interviews with the yoga instructor and clinicians each brought up culture as it related to the work they were doing in the Seeking Safety group. The specific cultural factors that emerged were race and HIV status. While the yoga instructor did not feel yoga 
was a barrier to any specific group clients, Clinician 1 noted that the intervention was conducted by three White women for a group of people of various minority, sexual and gender identities “... and so sometimes there's this kind of eye roll, like you don't, can't understand."

Clinician 2 also reported that "the group was facilitated by, in my tenure, consistently White clinicians and a White yoga instructor." She also noted that "I think it's interesting that some people think of yoga as a White thing even though it comes from cultures that are not White."

The clinicians and yoga instructor reported that the perception of yoga as portrayed in society may present a cultural challenge to clients. Clinician 1 shared that the impression is that "yoga studios have a beautiful, slender White woman standing up on a mountain top with the sun setting." She noted that bringing yoga to "a bunch of individuals who are struggling with so many minority identities involves the building of trust and normalization. Clinician 2 commented that she found it interesting that yoga is perceived as a White activity when, in fact, it is historically associated with people of color and was unable to bring that discussion into the class because it did not match with the agenda in the Seeking Safety protocol.

Both clinicians reported that most clients in the agency presented with HIV along with their addiction and trauma backgrounds. They also noted that clients with HIV belong to a culture that "becomes this kind of ingrained identity that they are unclean or not worthy of touch and they start to have a distrust of their own body . . . the stigma that goes along with HIV." Clinician 2 reported that clients have been told "that they should be ashamed of their bodies and what they did with their bodies." She believed that the yoga allowed clients to "engaged with their bodies" and were "affirmed by people around them." Both clinicians said that they believed the combination of yoga and Seeking Safety helped clients change their own relationship to their bodies and "it was reparative." 
Intervention Outcomes. Client self-report was an important measure of the efficacy of the Seeking Safety group enhanced with trauma-sensitive yoga. The biggest link to the yoga seems to be the breath work. Clients reported to the clinicians that they remembered the breath work when they become activated outside the agency and, as reported by the yoga instructor, ". . . often I've had people say I remembered to take three breaths in this really tense situation." Clinician 1 reports:

I remember a client telling me that he walked past, like, a needle on the street and he immediately started thinking about using and where he could go and all these things that just started that train (of thought). And he stopped walking and took the five deep breaths that the instructor talks about all the time and he said that he finished his walk to the bus, he got on, and he came here.

The yoga instructor reported that clients often come up to tell her about situations that occurred between group meetings. A client told her about practicing Tree Pose on a commuter train to reduce anger, which the instructor found encouraging if unexpected. She noted that purity of yoga is not the important factor in intervention outcomes, but the adaptation of the practice to the needs of the clients is paramount in constructing the intervention. Clinician 2 related her experience in the group to what she learned about trauma and noted that "... we know about how trauma impacts the body . . . and so I think it added value in the sense that it gave people extra skills and strategies to rely on, but also allowed them to work through what was going on for them somatically."

\section{Client Themes}

Client Response to Intervention. Clients were asked about their experiences with trauma-sensitive yoga as part of the Seeking Safety program. Almost all of the clients responded 
with positive feedback about yoga being incorporated with Seeking Safety, though one client noted that yoga was "not his thing" and that he did not enjoy the experience. All of the clients were able to articulate reasons the intervention has been included in the Seeking Safety intervention and shared about aspects they found particularly helpful. Many clients noted that the primary focus of the yoga program is to tolerate feelings and to be present and mindful.

Clients noted that the yoga helped them "stay in the moment" and focus on their breathing to regulate activation. Many clients reported that the yoga portion of the intervention taught them how to "sit in discomfort" and realize they can tolerate being uncomfortable longer than they thought. Clients noted that the simple exercises, as opposed to specific yoga poses were activities they remembered to try when they were feeling distress. Clients reported that "scrunching my toes" or "making a fist" were immediate and effective interventions they learned from participating in the enhanced Seeking Safety group. Participant 5 shared that "it really opened up ways to sit in your uncomfortableness." A member of the focus group noted: “. . it's really talking about mindfulness and, like, to breathe, and to make a fist when you're in a place, a reactive place ..."

Several participants shared that they thought the primary focus of having yoga as a part of the Seeking Safety group intervention was to get exercise. When asked about his experience with yoga as a part of the program Participant 11 noted "well, getting exercise" immediately. A participant in the focus group shared that he "... associated with, uh, like physical exercise. Like something to improve the physical body. And I just never put the two together that there was a mental part of it." Participant 2 noted that he felt that yoga "related to standing on your head." 
Participants described "coming into the moment" and feeling grounded as the yoga portion of the group started. Participants noted that they knew they did not have to be perfect following the suggested moves and that they had the option to participate from the chair if they were uncomfortable standing. A common theme addressed by the clients is that the yoga portion of the Seeking Safety intervention teaches them to "sit in their discomfort." The client responses to yoga were divided into three subthemes: (a) Client Use of Yoga; (b) Prior Beliefs About Yoga; and (c) Partnered Yoga.

Client Use of Yoga. Most clients noted that they did use techniques they had learned outside of class. One of the most common techniques cited was the use of controlled breathing. During the yoga portion of the class clients are instructed to take three deep breaths to center themselves. Clients in the focus group shared their experiences in learning that they can be uncomfortable longer than they thought possible and that they had options on how to address that discomfort. As one client noted, “... I kinda realized that it was for, to have a, concentrating on uncomfortable positions and now, you know, meditate and think your way through it." Another client reported that he incorporated yoga as a coping strategy that allowed him to "to sit in discomfort and feel safe."

Clients also reported that they became more aware of cravings and were willing to try yoga techniques to reduce or eliminate those cravings to use drugs or alcohol. Many noted using breathing techniques, centering techniques or other body movements to bring themselves into the moment and to tolerate craving sensations. Client 1 shared a moment when he had "the urge to get some dope, but I just closed my eyes and breathed because they tell me to breathe.” Client 3 mentioned that he has balled up his fist when dealing with people in difficult situations. Client five shared: 
...when we're frustrated or we're in a situation that we can't necessarily control, you know, I've used even small things like toe crunching techniques, like where you scrunch your toes to try to be present. Counting your breaths was one of them. Um, that's been really helpful, actually.

A common theme from the clients was that they would use the yoga techniques when they became activated on public transportation. Being on a bus or a train was identified by many of the clients as one of the most activating parts of their day because of the inherent stress involved with public transportation and the prevalence of drugs and drug dealing at transit stations. Client 7 described an occasion she used techniques she learned in the Seeking Safety group while on the train by taking a stance “. . . even though I didn't have somebody there who's doing the guiding meditation." Client 10 described an incident on the bus where "I put my leg on my thigh and lean in so I'm uncomfortable ... and that way I can be uncomfortable with what's going on around me." Client 13 shared that she used breathing and stretching techniques while she was visiting with family.

Prior Beliefs about Yoga. Several clients expressed that they did not have any experience with yoga before entering the program. Many expressed preconceived notions about yoga practice and they type of people who participated in yoga. Several members of the focus group shared that they saw yoga as a practice for White people or for people with a higher income status. No client seemed to be aware that yoga was established by people of color and that it traditionally has a spiritual component as well as its efficacy as a form of exercise. Client responses included "I never knew what it was", "it has something to do with exercise", and "it's like acting goofy". Other focus group participants reported they perceived yoga as "rigid" or "a feminine practice." Some African American members of the focus group noted prior beliefs about yoga as 
a White practice: "I saw all this stuff as what White people do . . I thought it was for White people."

I thought it was for rich White people also . . . but I also thought it came with this certain lifestyle, that I had to walk around representing yoga all the time and I had to carry stones with me ... and I mean I just thought it wasn't just like exercise, but I saw it as lifestyle.

Partnered Yoga. The yoga instructor and clinical staff facilitating the Seeking Safety introduced partnered yoga during a group discussion on boundaries. This was the first-time partnered yoga had been attempted with this group. Each member of the group was given the opportunity to participate or to observe. Client response was mixed, but the research team believed client experiences with partnered yoga were important to the process because this was the firsttime clients came in physical contact with each other in the Seeking Safety group. Clients that did participate in the partnered yoga generally had strong reactions to the experience, some of them reporting that they were uncomfortable being touched but were willing to try the experience anyway. Participant 5 reported:

...I got more out of that specific yoga class than anything from any of them. That partnered yoga. I've only attended one, but that, I got more out of that one than I can remember specifically.

Some clients chose not to participate, noting that the idea partnered yoga was "uncomfortable" or "awkward. One client reported that he was uncomfortable being touched by another man. Other clients reported feeling anxious or "irritated" with the idea of partnered yoga, but were willing to observe the activity. After the activity, the group related their feelings to the lesson in Seeking Safety about the creation of boundaries and the option to say yes or no when confronted with challenging situations. 


\section{Yoga As A Bridge Between Trauma and Addiction}

Because the Seeking Safety intervention is manualized to address co-occurring PTSD and substance abuse clients were asked if they saw a connection between the yoga practice in the Seeking Safety group and how they cope with trauma. Half of the clients $(n=7)$ reported that they did not see a connection between yoga and trauma. Half of the clients shared how they viewed yoga as a bridge to their understanding of trauma and addiction. Clients reported they became more aware of "recognizing when my addiction behavior kicks in" and appreciating the simplicity of the interventions. Client 4 shared that "it teaches us to sit in our discomfort. . how to get through cravings" and client 11 noted that "it keeps my mind focused on anything other than drugs or alcohol." Two clients articulated how they perceived trauma in relation to their addiction and how yoga helped to clarify that relationship. Client 10 noted that the interventions helps him "identify some behaviors ... that were a result of things that have happened" and to reconcile the uncomfortable feelings with the reality of his current level of perceived safety. Client 5 noted that he uses the breathing exercises taught to him in the yoga class and then distinguished his experience with trauma through a cultural lens not reflected in the trauma assessment:

... a lot of times trauma isn't necessarily the things that were in those questions ... my own sexual orientation, I was very uncomfortable in a setting like the gym and having to change clothes for physical education class and things of that nature. That was totally traumatizing for me.

A member of the focus group referred to the combination of Seeking Safety and yoga as "the perfect marriage" and that without the yoga Seeking Safety would be "just another group discussion, but now it has a whole other dimension added because of it." 


\section{Discussion}

Using Utilization-Focused Program Evaluation methodology we explored the efficacy of combining the Seeking Safety group intervention with Trauma-Sensitive (TS) yoga in an intensive outpatient addiction program by analyzing archival interviews collected by a community health agency that adapted and instituted the blended intervention. The combination of traumasensitive yoga and the Seeking Safety group intervention represents an innovation in counseling strategy and stakeholders at the institution recognized the ethical need to determine if the intervention was effective and congruent with the objectives of the program (Hadley \& Mitchell, 1995). Because this intervention was site specific, the results may not be generalizable to other practices and the focus of concern is the perceived results of the intervention by the evaluand. According to Daniels, Thompson, and Wolf (2016) the primary criteria used to determine the efficacy of a program or intervention are adequacy, utility and feasibility of the intervention and propriety of the evaluation.

\section{Adequacy}

The clinicians and most of the clients interviewed for this study expressed a strong belief that the combinations of the two interventions was stronger than either intervention presented alone. The majority of clients presented with high levels of trauma based on the Briere (2006) Initial Trauma Review (See Table 2.2) and with substance abuse problems great enough to justify taking part in an ASAM Level II substance abuse program, making them ideal participants in the Seeking Safety group intervention. Seeking Safety (Najavitz, 2002), which is considered a strong, evidence-based program, does not directly address the somatic elements of trauma, but somatic elements are the heart of trauma-sensitive yoga practice (West et al., 2016; van der Kolk, 2014; van der Kolk et al., 2014). 
Although research on Seeking Safety supports this program as an effective treatment, researchers conducting a recent meta-analysis cast doubt the effect size, noting only a medium reduction of trauma symptoms and decreasing substance use (Lenz et al., 2016). This study also noted that Seeking Safety was more effective with Caucasians or with single-minority groups than with groups with mixed ethnic identities. Najavits and Hein (2013) have noted that outcomes are "generally positive" (p. 442) and that clients were almost always in additional treatments while they were participating in Seeking Safety. Najavits and Weiss (1994) discussed the manualized nature of the protocol and posited that, despite manualization, clinicians may differ in delivering treatment which could affect outcomes. Clinicians in this study also noted that the language used in the Seeking Safety manual is not culturally current (i.e. no, or minimal, acknowledgment of gender and sexual minorities) and assumes literacy on the part of the clients.

It was noted by clinicians and clients that trauma-sensitive yoga, when presented by itself in the substance abuse program, did not generate "buy in" from the clients and elicited cultural barriers of its own. While several studies on the use of trauma-sensitive yoga have noted its effectiveness for people presenting with PTSD (Libby et al., 2012; Staples et al., 2013; West et al., 2016), the studies do not place a focus on simultaneous treatment of substance abuse and trauma, which is the great strength of the Seeking Safety program. Likewise, very little focus in these studies was placed on the specific issues of social stigma faced by racial, gender, and sexual minority individuals, and people living with HIV. The participants in this study raised specific cultural issues around yoga and the cultural backgrounds of the clients, thus illuminating a barrier to the "buy in" of these clients. Many of the clients articulated that yoga was perceived as both White and female, which hindered buy-in from the clients in some cases. 
The views of the majority of the clients about the purpose of the TS yoga/Seeking Safety combination and the experiences of the mental health and TS yoga practitioner were not congruent. The practitioners expressed a belief that the clients were aware of the connection between the use of trauma-sensitive yoga and clients' understanding of the somatic sequelae of trauma exposure. Data from the interviews did not support the idea that clients had a direct understanding of the somatic relationship, despite psychoeducation within the TS yoga/Seeking Safety intervention. It may be that the mental health practitioners and the TS yoga instructor overestimate the efficacy of their psychoeducation efforts and may want to re-examine how the reasoning for the combined intervention is presented to the clients. Nevertheless, the evidence provided by the data is that an understanding of the reasoning behind the interventions by the clients does not diminish the interventions themselves.

The possibility exists that any changes perceived by the clients and the clinicians can be explained by the Hawthorne or Westinghouse effects. The Hawthorne effect can be defined as a change in behavior spurred by the act of being observed or studied (Sedgwick \& Greenwood, 2015). The Westinghouse effect occurs when the environment is changed (such as an increase or decrease in lighting or a restructuring of schedules), leading to a change in behavior or productivity (Shaw \& Peterson, 2004). Both the Hawthorne and Westinghouse effects can lead to an increase in systematic errors when attributing causation to the physical changes rather than considering the effect of being observed or interacting with a new environment (Sedgwick \& Greenwood, 2015; Shaw \& Peterson, 2004). McCambridge, Witton, and Elbourne (2014) have noted that "there is no single Hawthorne effect" (p. 9) and to date, no research has identified the magnitude of the effect. However, Sedgwick and Greenwood (2015) have noted that the Hawthorne effect is subtle and the use of data triangulation can increase trustworthiness of the results 
attained. Such triangulation was used in this study along with other methods to increase trustworthiness recommended for qualitative studies (Hays et al., 2016).

\section{Utility}

The results of this program evaluation provide practical information that can be easily used by other practitioners, thus providing evidence of the utility of these combined interventions. By integrating Seeking Safety with trauma-sensitive yoga many of the inherent weaknesses of the two approaches were moderated or eliminated. The coordination of the program by the mental health clinicians conducting the Seeking Safety interventions and the yoga instructor led to adaptations of both programs that made them more effective for a majority of the participants and the participants were able to articulate advantages they had received from each part of the program. The data collected for this study show that providing coping tools for clients from both a Cognitive-Behavioral perspective (Seeking Safety) and a somatic perspective (TS yoga) in a coordinated manner increased the efficacy of both interventions with this population.

\section{Feasibility}

The results of study suggest that combination of Seeking Safety and TS yoga are both realistic and achievable. However, this combined intervention was developed at an agency in a large metropolitan area with access to a TS yoga instructor who was available to dedicate significant time to the agency. TS yoga instructors undergo extensive training to be certified (West, et al., 2016) and certified instructors may not be readily available outside of metropolitan areas. Researchers at the Veterans Administration utilized yoga instructors who did not identify as trauma-sensitive practitioners to provide yoga interventions focused on clients with PTSD and achieved significant improvement in hyperarousal symptoms indicating that the specific training may not be necessary (Staples et al., 2013). However, both practitioners and clients in this study 
noted the importance of having a TS yoga instructor provide the yoga intervention. The cost of the yoga instructor might also present a barrier for smaller or underfunded providers of substance abuse treatment.

\section{Propriety}

Every effort was made to conduct this research in an ethical manner. The research did not start until it was approved by the agency IRB process. Data were collected from clients by practitioners unaffiliated with the substance use program. Data were completely de-identified before a separate research team coded the interviews and those interviews were coded only after approval of the process by the University IRB. Participants were given an Informed Consent that was provided for them orally, and all participants were assured that they did not have to participate. Because the participants in the study identified themselves as trauma survivors and they completed the Briere (2004) Initial Trauma Review the interviews were conducted by professional counselors who could help if the clients experienced hyperarousal or abreaction during the interview process. No participant identified the need for further counseling after the interviews, which is consistent with prior research on the experiences of trauma survivors (Edwards \& Sylaska, 2016; Griffin et al., 2003; Neilson et. al., 2016).

\section{Implications and Directions for Future Research and Limitations}

Findings from this study provide evidence that the combination of the Seeking Safety group intervention and trauma-sensitive yoga is not only an effective strategy for the participating agency but they also indicate that the combined intervention is stronger than either intervention alone. These results are consistent with other studies that have incorporated traumasensitive yoga for use with trauma survivors (Emerson et al., 2012; Staples et al., 2013; van der Kolk, 2014). Based on these findings, clinicians at other agencies or practices who currently uti- 
lize the Seeking Safety group intervention may want to consider the addition of trauma-sensitive yoga if that is feasible for that agency or practice. If a trauma-sensitive yoga practitioner is not available or cannot be employed because of budgetary constraints, the results of this study would suggest consideration of the basic somatic elements (e.g. toe scrunching) be taught to clients as an adjunct to the manualized Seeking Safety intervention.

While this study indicates the success of an innovation in counseling practice, several limitations are present. Every effort was made per standard qualitative methodology to reduce the biases inherent in evaluating innovation in counseling (Hays et al., 2016). Nevertheless, biases in favor of this intervention were evident and demonstrate the tension between the need to provide evidence of the efficacy of an intervention (Smith, 2010) and the potential for creating a self-fulfilling prophecy of adequacy. This argument can be countered by considering the Dodo Bird Hypotheses as presented by Wampold (2001). The Dodo Bird Hypotheses, a theory postulated by Rosenzweig in 1936, borrows from the story in Alice's Adventures in Wonderland in which the Dodo Bird proclaims, "everybody has won, and all must have prizes" (p. 72). The hypothesis suggests that all psychotherapies, regardless of their specific components, produce equivalent outcomes. In Wampold's (2001) contextual model of psychological intervention the therapist's belief in the treatment is a necessary component for all treatments and that all research designs contain bias towards the treatment. Acknowledging biases through positionality statements at the beginning of this study reduces the limitation in the study but does not eliminate it. The use of an outside auditor and a coding team consisting of members not related to the intervention reduced the bias limitation as well.

Because this was a qualitative program evaluation that focused on the use of the intervention in a specific setting the results may not translate to other agencies or settings. Archival 
data were used, and subjects were de-identified rendering a mixed method analysis of the data provided Briere's Initial Trauma Review moot, and might have strengthened the study results. Although we believe the data collected were thorough representations of the clients' experience our sample size was necessarily limited to current participants in the substance abuse program at the agency and a more longitudinal study might produce different results. Continuation of this research in additional settings using mixed methods or the development of a quantitative prepost- experimental design may indicate a general efficacy of the treatment and recommend a broader adoption in clinical settings.

\section{Conclusion}

This chapter outlined a Utilization Focused program evaluation conducted at a mental health agency in a large metropolitan city. The evaluation analysis indicated that the combination of the Seeking Safety group counseling intervention with trauma sensitive yoga is more ef-

fective than either intervention conducted on its own. While this combined intervention may not be appropriate or feasible in other clinical settings, it may represent on method of increasing efficacy in standard addiction and trauma treatment protocols. The positive effect of the interventions appears to be predicated on the trauma instructor having advanced skills in trauma sensitive yoga practice and coordination between the yoga instructor and the clinicians conducting the psychoeducation interventions in the Seeking Safety manual. 


\section{References}

Amaro, H., Chernoff, M., Brown, V., Arevalo, S., \& Gatz, M. (2007) Does integrated traumasensitive substance use treatment increase treatment retention? Journal of Community Psychology, 35 (7), 845-862. doi: dx.doi.org/10.1002/jcop.20185

American Counseling Association (2014). Code of ethics. Alexandria, VA: Author.

American Psychiatric Association. (2015). Diagnostic and statistical manual of mental disorders: DSM-5. Washington, D.C: American Psychiatric Association.

Astramovich, R. \& Coker, K. (2007). Program evaluation: The accountability bridge model for counselors. Journal of Counseling \& Development, 85(2), 162-172. doi: http://dx.doi.org/10.1002/j.1556-6678.2007.tb00459.x

Barrett, N. (2013). Program evaluation: A step-by-step guide. Urbana, IL: Sunnycrest Press.

Barry, C., Abraham, K., Weaver, K., \& Bowersox, N. (2016). Innovating team-based outpatient mental health care in the Veterans Health Administration: Self-perceived benefits and challenges to pilot implementation of the behavioral health interdisciplinary program (BHIP). Psychological Services, 13 (2), 148-155. doi: 10.1037/ser0000072

Begun J. \& Kaissi, A. (2005). An exploratory study of healthcare strategic planning in two metropolitan areas. Journal of Healthcare Management, 50(4), 264-274.

Boden, M., Kimmerling, R., Jacobs-Lentz, J., Bowman, D., Weaver, C., Carney, D., . . \& Trafton, J. (2012). Seeking safety treatment for male veterans with a substance use disorder and post-traumatic stress disorder symptomology. Addictions, 107 (3), 578-586. doi: http://dx.doi.org/10.1111/j.1360-0443.2011.03658.x 
Bogdan, R. \& Biklen, S. (2007). Research for education: An introduction to theories and methods. New York: Pearson.

Briere, J. \& Scott, C. (2006). Principles of trauma therapy: A guide to symptoms, evaluation, and treatment. Thousand Oaks: Sage.

Caplan, M., Portillo, A., \& Seely, L. (2013). Yoga psychotherapy: The integration of western psychological theory and ancient yogic wisdom. The Journal of Transpersonal Psychology, 45 (2), 139-158.

Cardaciotto, L. \& Tonrey, D. (2012). The training, value and reality of master's-level mental health counselors. Journal of Cognitive Psychotherapy: An International Quarterly, 26 (3), 183-195. doi: 10.1891/0889-8391.26.3.183

Carter, J., Gerbarg, P., Brown, R., Ware, R., D’Ambrosio, C., Anand, L. . . . \& Katzman, M. (2013). Multi-component yoga breath program for Vietnam veteran post-traumatic stress disorder: Randomized controlled trial. Journal of Traumatic Stress Disorders and Treatment, 2 (3). doi: 10.4172/2324-8947.1000108

Clark, C., Lewis-Dmello, A., Anders, D., Parsons, A., Nguyen-Feng, V., Henn, L., \& Emerson, D. (2014). Trauma-sensitive yoga as an adjunct mental health treatment in group therapy for survivors of domestic violence: A feasibility study. Complementary Therapies in Clinical Practice, 20, 152-158. doi: 10.1016/j.ctcp.2014.04.003

Cocozza, J., Jackson, E., Hennigan, K., Morrissey, J., Reed, B., Fallot, R., \& Banks, S. (2005). Women, co-occurring disorders and trauma: Program-level effects. Journal of Substance Abuse Treatment, 28 (2), 109-119. doi: http://dx.doi.org/10.1016/j.jsat.2004.08.010

Courtois, C. \& Ford, J. (Eds.). (2009). Treating complex stress disorders: An evidence-based guide. New York: Guilford Press. 
Daniels, M., Thompson, E., \& Wolf, C. (2016). Program evaluation. In Sheperis, C., Young, J., Scott., \& Daniels, M. (Eds.), Counseling research and mycounselinglab with pearson extext access card: Quantitative, qualitative, and mixed methods. New York, NY:Pearson College Division.

Da Silva, T., Ravindran, L., \& Ravindran, A. (2009). Yoga in the treatment of mood and anxiety disorders: A review. Asian Journal of Psychiatry, 2, 6-16. doi: 10.1016/j.2008.12.002

Desai, R., Harpaz-Rotem, I., Najavitz, L., \& Rosenheck, R. (2008). Impact of the seeking safety program on clinical outcomes among homeless female veterans with psychiatric disorders. Psychiatric Services, 59 (9), 996-1003. doi:

http://dx.doi.org/10.1176/ps.2008.59.9.996

Edwards, K. \& Sylaska, K. (2016). Reactions to participating in intimate partner violence and minority stress research: A mixed methodological study of self-identified lesbian and gay emerging adults. Journal of Sex Research, 53 (6), 655-665. doi:

$10.1080 / 00224499.2015 .1035428$

Emerson, D., Sharma, R., Chaudhry, S., \& Turner, J. (2009). Trauma-sensitive yoga: Principles, practice, and research. International Journal of Yoga Therapy, 19, 123-128.

Farley, M., Golding, J., Young, G., Mulligan, M., \& Minkoff, J. (2004). Trauma history and relapse probability among patients seeking substance abuse treatment. Journal of Substance Abuse Treatment, 27, 161-167. doi: 10.1016/j.sat.2004.06.006

Foa, E., Keane, T., Friedman, M., \& Cohen, J. (Eds.) (2009). Effective treatments for PTSD: Practice guidelines from the International Society for Traumatic Stress Studies. New York: Guilford Press. 
Funnell, S. \& Rogers, P. (2011). Purposeful program theory: Effective use of theories of change and logic models. San Francisco: Jossey-Bass.

Ghee, A., Bolling, L., \& Johnson, C. (2009). The efficacy of a condensed seeking safety intervention for women in residential chemical dependence treatment at 30 days posttreatment. Journal of Child Sexual Abuse, 18, 475-488. doi: 10.1080/10538710903183287

Griffin, M., Resick, P., Waldrop, A., \& Mechanic, M. (2003). Participation in trauma research: Is there evidence of harm? Journal of Traumatic Stress, 16 (3), 221-227. doi: 0894-9867/03//0600-0221/1

Guba, E. \& Lincoln, Y. (1989). Fourth generation evaluation. New Park, CA; Sage.

Hadley, R. \& Mitchell, L. (1995). Counseling research and program evaluation. Belmont, CA: Brooks/Cole.

Hallgren, M., Romberg, K., Bakshi, A., \& Andreasson, S. (2014). Yoga as an adjunct treatment for alcohol dependence: A pilot study. Complementary Therapies in Medicine, 22, 441445. doi: 10.1016/j.ctim.2014.03.003

Hays, D., Wood, C., Dahl, H., \& Kirk-Jenkins. (2016). Methodological rigor in Journal of Counseling \& Development qualitative research articles: A 15-year review. Journal of Counseling \& Development, 94, 172-183. doi: 10.1002/jcad.12074

Jaffe, A., DiLillo, D., Hoffman, L., Haikalis, M, \& Dykstra, R. (2015). Does it hurt to ask? A meta-analysis of participant reactions to trauma research. Clinical Psychology Review, 40, 40-56. doi: 10.1016/j.cpr.2015.05.004

Kessler, R., Sonnega, A., Bromet, E., Hughes, M., \& Nelson, C. (1995). Post-traumatic stress disorder in the National Cormorbidity Survey. Archives of General Psychiatry, 52, 10481060. doi: dx.doi.org/10.1001/archpsyc.1995.03950240066012 
Kirkwood, G., Rampes, H., Tuffrey, V., Richardson, J., \& Pilkington, K. (2005). Yoga for anxiety: A systematic review of the research evidence. British Journal of Sports Medicine, 39 (12), 884-891. doi: http://dx.doi.org/10.1136/bjsm.2005.018069

Kline, W. (2008). Developing and submitting credible qualitative manuscripts. Counselor Education \& Supervision, 47, 210-217. doi: http://dx.doi.org/10.1002/j.15566978.2008.tb00052.x

Lenz, A., Henesy, R., \& Callender, K. (2016). Effectiveness of Seeking Safety for co-occurring posttraumatic stress disorder and substance use. Journal of Counseling \& Development, 94, 51-61. doi: 10.1002/jcad.12061

Libby, D., Reddy, F., Pilver, C., \& Desai, R. (2012). The use of yoga in specialized VA PTSD treatment programs. International Journal of Yoga Therapy, 22, 79-87.

Lilly, M. \& Hedlund, J. (2010). Healing childhood sexual abuse with yoga. International Journal of Yoga Therapy, 20, 120-128.

Lincoln, Y. \& Guba, E. (1985). Naturalistic inquiry. Newberry Park, CA: Sage.

Lincoln, Y. \& Guba, E. (1986). Research, evaluation, and policy analysis: Heuristics for disciplined inquiry. Policy Studies Review, 5 (3), 546-565. doi: http://dx.doi.org/10.1111/j1541-1338.1986.tb00429.x

McCambridge, J., Witton, J., \& Elbourne, D. (2014). Systematic review of the Hawthorne effect: New concepts are needed to study research participation effects. Journal of Clinical Epidemiology, 67 (3), 267-277. doi: http://dx.doi.org.ezproxy.gsu.edu/10.1016/j.jclinepi.2013.08.015 
McIver, S., O’Halloran, P., \& McGartland, M. (2009). Yoga as a treatment for binge eating disorder: A preliminary study. Complementary Therapies in Medicine, 17 (4), 196-202. doi: http://dx.doi.org/10.1016/j.ctim.2009.05.002

Mitchell, K., Dick, A., DiMartino, D., Smith, B., Niles, B., Koenen, K., \& Street, A. (2014). A pilot study of a randomized controlled trial of yoga as an intervention for PTSD symptoms in women. Journal of Traumatic Stress, 27, 121-128. doi: 10.1002/jts.21903

Morgan-Lopez, A., Saavedra, L., Hien, D., Campbell, A., Wu, E., \& Ruglass, L. (2013). Synergy between seeking safety and twelve-step affiliation on substance use outcomes for women. Journal of Substance Abuse Treatment, 45, 179-189. doi: 10.1016/j.sat.2013.01.015

Morgan-Lopez, A., Saavedra, L., Hien, D., Campbell, A., Wu, E., Ruglass, L. . . \& Bainter, S. (2014). Indirect effects of 12-session seeking safety on substance use outcomes: Overall and attendance class-specific effects. American Journal on Addictions, 23, 218-225. doi: 10.1111/j.1521-0391.2014.12100.x

Morell, J. (2010). Evaluation in the face of uncertainty. New York, NY: Guilford Press Najavitz, L. (2002). Seeking safety: A treatment manual for PTSD and substance abuse. New York: Guilford Press.

Najavitz, L., Gallop, R., \& Weiss, R. (2006). Seeking safety therapy for adolescent girls with PTSD and substance use disorder: A randomized controlled trial. The Journal of Behavioral Health Services \& Research, 33 (4), 453-463. doi: http://dx.doi.org/10.1007/s11414-006-9034-2

Najavitz, L. \& Hien, D. (2013). Helping vulnerable populations: A comprehensive review of the treatment outcome literature on substance use disorder and PTSD. Journal of Clinical Psychology in Session, 69 (5), 433-479. doi: 10.1002/jclp.21980 
Najavitz, L., Smylie, D., Johnson, K., Lung, J., Gallop, R., \& Classen, C. (2013). Seeking safety therapy for pathological gambling and PTSD: A pilot outcome study. Journal of Psychoactive Drugs, 45 (1), 10-16. doi: 10.1080/02791072.2013.763557

Najavitz, L. \& Weiss, R. (1994). The role of psychotherapy in treatment of substance-use disorders. Harvard Review of Psychiatry, 2 (2), 84-96. doi: http://dx.doi.org/10.3109/10673229409017121

Nielson, T. (2015). Practice-based research: Meeting the demands of program evaluation through the single-case design. Journal of Mental Health Counseling, 37 (4), 364-376. doi: http://dx.doi.org/10.17744/mehc.37.4.07

Nielson, L., Hanson, M., Elklit, A., \& Bramson, R. (2016). Sexual assault victims participating in research: Causing harm when trying to help? Archives in Psychiatric Nursing, 30, 412-417. doi: 10.1016/apnu.2016.01.017

Norman, S., Wilkins, K., Tapert, S., Lang, A., \& Najavitz, L. (2010). A pilot study of seeking safety therapy with OEF/OIF veterans. Journal of Psychoactive Drugs, 42 (1), 83-87. doi: http://dx.doi.org/10.1080/02791072.2010.10399788

Patitz, B., Anderson, M., \& Najavitz, L. (2014). An outcome study of seeking safety with rural community-based women. Journal of Rural Mental Health, 39 (1), 54-58. doi: $10.1037 / \mathrm{mh} 0000015$

Patton, M. (2015a). Qualitative research and evaluation methods. Thousand Oaks, CA: Sage. Patton, M. (2015b). The sociological roots of utilization-focused evaluation. The American Sociologist, 46(4), 457-462. doi: 10.1007/s12108-015-9275-8 
Pearlman, L. \& Caringi, J. (2009). Living and working self-reflectively to address vicarious trauma. In Courtois, C. and Ford, J. (Eds.) Treating Complex Stress Disorders, 202-242, New York: Guilford.

Posadzki, P., Choi, J., Soo Lee, M., \& Ernst, E. (2014). Yoga for addictions: A systematic review of randomized clinical trials. Focus on Alternative and Complementary Therapies, 19 (1), 1-8. doi: http://dx.doi.org/10.1111/fct.12080

Posadzki, P. \& Ernst, E. (2011). Yoga for low back pain: A systematic review of randomized clinical trials. Clinical Rheumatology, 30 (9), 1257-1262. doi: http://dx.doi.org/10.1007/s10067-011-1764-8

Schmitz, C., Parsons, B., \& Juvenile Justice Evaluation Center. (2004). Everything you wanted to know about logic models but were afraid to ask. Washington, DC: Juvenile Justice Evaluation Center.

Sedgwick, P. \& Greenwood, N. (2015). Understanding the Hawthorne effect. British Medical Journal, 351. doi: 10.1136/bmj.h4672

Serris, J. \& Byrne, G. (2011). A systematic review of insomnia and complementary medicine. Sleep Medicine Reviews, 15 (2), 99-106. doi: http://dx.doi.org/10.1016/jsmrv.2010.04.001

Shannahoff-Khalsa, D. (2004). An introduction to Kundalini yoga meditation techniques that are specific to the treatment of psychiatric disorders. The Journal of Alternative and Complementary Medicine, 10 (1), 91-101. doi: http://dx.doi.org/10.1089/107555304322849011

Shaw, G. \& Peterson, M. (2004). Keeping Mozart in mind. San Diego: Elsivier Academic Press. 
Smith, M. (2010). Handbook of program evaluation for social work and health professionals. New York, NY: Oxford.

Stake, R. (2010). Qualitative research: Studying how things work. New York: Guilford.

Staples, J., Hamilton, M., \& Uddo, M. (2013). A yoga program for the symptoms of posttraumatic stress disorder in veterans. Military Medicine, 178 (8), 854-860. doi: 10.7205/MILMED-D-12-00536

Strauch, I. (2001). An Adlerian reconceptualization of traumatic reactions. The Journal of Individual Psychology, 57 (3), 246-258.

Tayabas, L., Leon, T. \& Espino, J. (2014). Qualitative evaluation: A critical approach and interpretive complementary approach to improve health programs and services. International Journal of Qualitative Studies on Health and Wellbeing, 9.

Telles, S., Singh, N., \& Balkrishna, A. (2012). Managing mental health disorders resulting from trauma through yoga: A review. Depression Research \& Treatment. doi: $10.1155 / 2012 / 4015013$.

Van der Kolk, B. (2014). The body keeps the score. New York, NY: Penguin Books.

Van der Kolk, B., Stone, L., West, J., Rhodes, A, Emerson, D, Suvak, M., \& Spinazzola, J. (2014). Yoga as an adjunctive treatment for posttraumatic stress disorder: A randomized controlled trial. Journal of Psychiatry, 75 (6). 559-565. doi: 10.4088/JCP.13m08561.

Wampold, B. (2001). The great psychotherapy debate. New York: Routledge.

Wealde, L. (2004). Dissociation and meditation. Journal of Trauma and Dissociation, 5 (2), 147-162. Doi: 10.1300/J229v05n02_08. 
West, J, Liang, B, \& Spinazzola, J. (2016). Trauma sensitive yoga as a complementary treatment for posttraumatic stress disorder: A qualitative descriptive analysis. International Journal of Stress Management. Advance online publication. doi: http://dx.doi.org/10.1037/str000040

Wolff, N., Huening, J., Shi, J., Frueh, C., Hoover, D., \& McHugo, G. (2015). Implementation and effective integrated trauma and addiction treatment for incarcerated men. Journal of Anxiety Disorders, 30, 66-80. doi: 10.1016/j.janxdis.2014.10.009 


\title{
APPENDICES
}

\section{Appendix A - Informed Consent for Individual Interview}

\section{Positive Impact Health Centers - Midtown}

\section{INFORMED CONSENT}

Title: A Qualitative Program Evaluation on the Efficacy of Combining Traumasensitive Yoga Practice with the Seeking Safety Group Protocol

\author{
Principal Investigator: Thomas Murphy, MS, APC, NCC \\ IRB Supervisor: Gwen Davies, $\mathrm{PhD}$
}

\section{Purpose: \\ You are invited to be in a research study.}

This is a study about your experiences in the Seeking Safety group. We are talking to people who have attended the group at Positive Impact. We will ask you some questions about the group lessons and yoga. We will talk for about 15 minutes and will ask you about yourself and to answer some questions from a list before we talk.

\section{What Will Happen:}

You do not have to be a part of this study. Nothing bad will happen if you do not want to do this. If you want to continue we will record our talk. Your name will not be used. We want to know how you feel, both good and bad, about yoga in the Seeking Safety group. The interview will be typed by someone who does not know you. We will erase your name and any names you might tell us about. You can stop at any time.

Some of the questions might be uncomfortable for you. You do not have to answer them. If you feel uncomfortable and need to talk to someone let your interviewer know and they will get someone for you.

III. Risks:

We do not think there is any risk to you. These questions might be uncomfortable. You can stop at any time. Counselors at Positive Impact are here to help if you if you need. You can also talk to Gwen Davies if you don't feel right about these questions.

\section{Benefits:}

You may not get anything from being in this study, but we hope we can help others who come to Positive Impact by looking at how yoga and Seeking Safety work together. 
V. Voluntary:

Being in this study is up to you. You do not have to be in this study. You can skip questions if you want. You can stop at any time if you want.

VI. Privacy:

We will keep all of your information private. Only Tom Murphy, Rico Curtis-Davidson and Moneta Sinclair will see your answers. We will make sure any names will be marked out. Your answers will be given a number so your name is private. Your name and any other personal information will be kept in a locked computer and will not be kept with your answers.

VII. Contact Persons:

You may contact Gwen Davies at Positive Impact if you have any concerns or questions about this study.

\section{Copy of Consent Form to Subject:}

We will give you a copy of this form and we will keep a copy.

The talk will be recorded.

I have been given all of the information about this study and agree to answer the questions. I know that I can stop at any time. I know the talk will be recorded and typed.

Client Signature Date

Researcher Signature Date

Flesch-Kincaid $=80.7$, Grade 4.6 , School Level $-5^{\text {th }}$ Grade . 
Appendix B - Demographic Trauma Review adapted from Briere \& Scott (2006)

Positive Impact Health Centers - Midtown

\section{CLIENT DATA}

Because the evaluators did not assume participant literacy, the following data were gathered verbally by the evaluator.

Title: A Qualitative Program Evaluation on the Efficacy of Combining Traumasensitive Yoga Practice with the Seeking Safety Group Protocol

Participant Age:

Participant Racial Identity:

$\square$ White

$\square$ Black

$\square$ Asian

$\square$ Hispanic

Multi-Racial

$\square$ Bi-Racial

$\square$ How would the participant like to be identified: $?$

Participant Gender Identity:

$\square$ Male

$\square$ Female

$\square$ Transgender

$\square$ Gender-Queer

$\square$ How would the participant like to be identified: ?

Participant Relational (Sexual) Orientation:

$\square$ Straight/Heterosexual

$\square$ Gay 
Bi-Sexual

Pan-Sexual

Asexual

How would the participant like to be identified: $?$

Participant current status at Positive Impact:

$\square$ IOP

$\square \mathrm{CCP}$

$\square$ Past IOP or CCP but no longer enrolled in addiction program.

Participant Identified Substance Use leading to program admission:

\section{ETOH}

$\square$ THC

$\square$ Methamphetamine

$\square$ Cocaine

$\square$ MDMA

$\square$ Heroin/Opioids/Opiates

$\square$ Other:

Participant's identified religious or spiritual affiliation/identity:

Participant's trauma background:

$\square$ Before Age 18 parent or another adult hurt or punished you in a way that left bruises, cuts, scratches or made you bleed.

If YES, please follow up with:

- When this happened, did you ever feel very afraid, horrified or helpless?

○ Did you ever think you might be injured or killed?

O

$\square$ Before Age 18 did anyone who was 5 or more years older than you ever do something sexual with you or to you? 
If YES, please follow up with:

- When this happened, did you ever feel very afraid, horrified or helpless?

○ Did you ever think you might be injured or killed?

Before Age 18 did anyone who was less than 5 years older than you ever do something sexual to you that was aginst your will or that happened when you couldn't defend yourself?

If YES, please follow up with:

- When this happened, did you ever feel very afraid, horrified or helpless?

○ Did you ever think you might be injured or killed?

○

Before Age 18 were you ever involved in a serious fire, earthquake, flood or other disaster?

If YES, please follow up with:

- When this happened, did you ever feel very afraid, horrified or helpless?

○ Did you ever think you might be injured or killed?

O

Before Age 18 were you ever involved in a serious automobile accident?

If YES, please follow up with:

- When this happened, did you ever feel very afraid, horrified or helpless?

○ Did you ever think you might be injured or killed?

Before Age 18 did you ever see someone else get killed or badly hurt?

If YES, please follow up with:

- When this happened, did you ever feel very afraid, horrified or helpless?

○ Did you ever think you might be injured or killed?

$\square$ Since Age 18 or older has something sexual ever been done to you against your will or when you couldn't defend yourself (for example, when you were asleep or intoxicated)? If YES, please follow up with:

- When this happened, did you ever feel very afraid, horrified or helpless? 
○ Did you ever think you might be injured or killed?

$\square$ Since Age 18 or older have you ever been slapped, hit or nearly strangle in a sexual or marital relationship?

If YES, please follow up with:

- When this happened, did you ever feel very afraid, horrified or helpless?

○ Did you ever think you might be injured or killed?

Since Age 18 or older, have you ever been physically attacked, assaulted, stabbed, or shot by someone who wasn't a sex partner or husband/wife?

If YES, please follow up with:

When this happened, did you ever feel very afraid, horrified or helpless?

○ Did you ever think you might be injured or killed?

Since Age 18 or older, have you ever experienced combat or fought in a war?

If YES, please follow up with:

- When this happened, did you ever feel very afraid, horrified or helpless?

○ Did you ever think you might be injured or killed?

Since Age 18 or older, were you ever involved in a serious automobile accident?

If YES, please follow up with:

When this happened, did you ever feel very afraid, horrified or helpless?

○ Did you ever think you might be injured or killed?

$\square$ Since Age 18 or older, were you ever involved in a serious fire, earthquake, flood or other disaster?

If YES, please follow up with:

-When this happened, did you ever feel very afraid, horrified or helpless?

○ Did you ever think you might be injured or killed? 
$\square$ In this country, have you ever been hit, beaten, assaulted or shot by the police or other law enforcement officials, during or after an arrest, or at some other time?

If YES, please follow up with:

When this happened, did you ever feel very afraid, horrified or helpless?

○ Did you ever think you might be injured or killed?

Since you were 18 or older, did you ever see someone else killed or badly hurt?

If YES, please follow up with:

- When this happened, did you ever feel very afraid, horrified or helpless?

○ Did you ever think you might be injured or killed?

○

If YES to any of these questions, please follow up with:

When this happened, did you ever feel very afraid, horrified or helpless?

$\square$ Did you ever think you might be injured or killed? 


\section{Appendix C - Semi-structured Individual Interview Questions}

Trauma-sensitive Yoga Questions for Seeking Safety Semi-Structured Interviews

1. The seeking safety group includes yoga as part of the group. Prior to doing yoga in the group, what did you believe or think about yoga? How do you think your culture or background may have influenced your beliefs about yoga?

2. Please tell us your experiences with yoga as a part of the program.

3. The Seeking Safety group focuses on the relationship between trauma and addiction. Does the yoga part of the meeting help you understand the relationship between trauma and addiction?

4. Have you ever used the yoga techniques you learned in Seeking Safety while you were not at Positive Impact? If so, please tell us about a time or times that you remember using the yoga techniques when you were not at Positive Impact.

5. What else would you like to tell us about your experiences with yoga in the Seeking Safety group? 


\section{Appendix D - Informed Consent for Focus Group}

\section{Positive Impact Health Centers - Midtown}

\section{INFORMED CONSENT FOCUS GROUP}

Title: A Qualitative Program Evaluation on the Efficacy of Combining Traumasensitive Yoga Practice with the Seeking Safety Group Protocol

Principal Investigator: Thomas Murphy, MS, APC, NCC

IRB Supervisor: Gwen Davies, $\mathrm{PhD}$

\section{Purpose:}

You are invited to be in a research focus group.

This is a study about your experiences in the Seeking Safety group. We are talking to people who have attended the group at Positive Impact. We will ask you some questions about the group lessons and yoga.

\section{What Will Happen:}

You do not have to be a part of this focus group. Nothing bad will happen if you do not want to do this. If you want to continue we will record our talk. Your name will not be used. We want to know how you feel, both good and bad, about yoga in the Seeking Safety group. The interview will be typed by someone who does not know you. We will erase your name and any names you might tell us about. You can stop at any time.

Some of the questions might be uncomfortable for you. You do not have to answer them. If you feel uncomfortable and need to talk to someone let your interviewer know and they will get someone for you.

III. Risks:

We do not think there is any risk to you. These questions might be uncomfortable. You can stop at any time. Counselors at Positive Impact are here to help if you if you need. You can also talk to Gwen Davies if you don't feel right about these questions.

IV. Benefits:

You may not get anything from being in this study, but we hope we can help others who come to Positive Impact by looking at how yoga and Seeking Safety work together.

V. Voluntary:

Being in this focus group is up to you. You do not have to be in this focus group. You can leave at any time if you want. 
VI. Privacy:

We will keep all of your information private. Only Tom Murphy, Rico Curtis-Davidson and Moneta Sinclair will see your answers. We will make sure any names will be marked out. Your answers will be given a number so your name is private. Your name and any other personal information will be kept in a locked computer and will not be kept with your answers.

VII. Contact Persons:

You may contact Gwen Davies at Positive Impact if you have any concerns or questions about this study.

\section{Copy of Consent Form to Subject:}

We will give you a copy of this form and we will keep a copy.

The talk will be recorded.

I have been given all of the information about this study and agree to answer the questions. I know that I can stop at any time. I know the talk will be recorded and typed.

Client Signature Date

Researcher Signature Date

Flesch-Kincaid $=80.7$, Grade 4.6, School Level $-5^{\text {th }}$ Grade . 


\section{Appendix E - Questions for Seeking Safety Semi-Structured Focus Group}

Trauma-sensitive Yoga Questions for Seeking Safety Semi-Structured Focus Group

What is your understanding of what Seeking Safety is about?

The Seeking Safety group includes yoga as part of the group. Prior to doing yoga in the

group, what did you believe or think about yoga? How do you think your culture or background may have influenced your beliefs about yoga?

Please tell us your experiences with yoga as a part of the program.

Why do you think yoga is included in the Seeking Safety group?

The Seeking Safety group focuses on the relationship between trauma and addiction.

Does the yoga part of the meeting help you understand the relationship between trauma and addiction?

Is the Seeking Safety group helpful for you? If it is helpful, how is it helpful?

Is the yoga part of the Seeking Safety group helpful to you? If it is helpful, how is it helpful?

Have you ever used the yoga techniques you learned in Seeking Safety while you were not at Positive Impact? If so, please tell us about a time or times that you remember using the yoga techniques when you were not at Positive Impact.

The yoga practice sometimes includes what we call "partnered yoga" where you may work in pairs or as part of a group. Have you participated or watched the partnered yoga? What was the experience like either participating or watching?

What else would you like to tell us about your experiences with yoga in the Seeking Safety group? 